\title{
Kalirin-RAC controls nucleokinetic migration in ADRN-type neuroblastoma
}

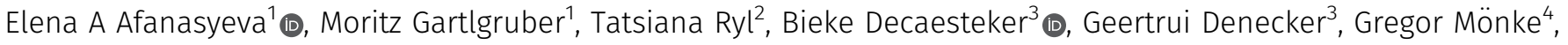 \\ Umut H Toprak ${ }^{1}$, Andres Florez ${ }^{1,5}$ ๑ , Alica Torkov ${ }^{1}$, Daniel Dreidax ${ }^{1}$, Carl Herrmann ${ }^{6}$, Konstantin Okonechnikov ${ }^{7}$, Sara Ek $^{8}$, \\ Ashwini Kumar Sharma ${ }^{9,10}$, Vitaliya Sagulenko ${ }^{11}$ (1), Frank Speleman ${ }^{3}$, Kai-Oliver Henrich ${ }^{1}$, Frank Westermann ${ }^{1}$ (1)
}

The migrational propensity of neuroblastoma is affected by cell identity, but the mechanisms behind the divergence remain unknown. Using RNAi and time-lapse imaging, we show that ADRN-type NB cells exhibit RAC1- and kalirin-dependent nucleokinetic (NUC) migration that relies on several integral components of neuronal migration. Inhibition of NUC migration by RAC1 and kalirin-GEF1 inhibitors occurs without hampering cell proliferation and ADRN identity. Using three clinically relevant expression dichotomies, we reveal that most of up-regulated mRNAs in RAC1- and kalirinGEF1-suppressed ADRN-type NB cells are associated with low-risk characteristics. The computational analysis shows that, in a context of overall gene set poverty, the upregulomes in RAC1- and kalirinGEF1-suppressed ADRN-type cells are a batch of AU-rich elementcontaining mRNAs, which suggests a link between NUC migration and mRNA stability. Gene set enrichment analysis-based search for vulnerabilities reveals prospective weak points in RAC1- and kalirinGEF1-suppressed ADRN-type NB cells, including activities of H3K27and DNA methyltransferases. Altogether, these data support the introduction of NUC inhibitors into cancer treatment research.

DOI 10.26508/Isa.201900332 | Received 4 February 2019 | Revised 12 February 2021 | Accepted 17 February 2021 | Published online 3 March 2021

\section{Introduction}

Cell migration is the process that occurs during normal embryogenesis, wound healing, immune responses, and metastasis. Accumulated evidence suggests parallelism between metastatic dissemination of tumor cells and migratory processes during embryogenesis. A plethora of genes governing migration during embryogenesis are also involved in the metastatic process (van Zijl et al, 2011). Active cell migration is essential throughout the whole metastatic process occurring through a sequence of phases including local invasion into the tissue, extravasation into the blood or lymphatic vessels, transit, attachment, intravasation into tissue, colonisation, and proliferation (Tsai \& Yang, 2013). The embryonic program of epithelial-mesenchymal transition (EMT) drives cancer cell motility during the dissemination of carcinomas (Thiery et al, 2009). Although transcriptional control and mechanisms of EMT have been elucidated in epithelial cancers, the relevance of EMT to the metastatic process in non-epithelial malignancies, particularly, those of neuroectodermal origin, including neuroblastoma (NB), remains unaddressed. NB, a paediatric malignancy, is thought to be a result of impaired differentiation of neural crest-derived progenitor cells, which promotes the expansion of a population of cells susceptible to the secondary transforming events, that is, deregulation of MYCN via amplification, or c-MYC activation (Westermann et al, 2008; Pei et al, 2013). NBs in children older than 18 mo are metastatic and are associated with a poor survival rate. However, NBs in children younger than 18 mo, especially those with the absence of MYCN amplification and a particular pattern of metastasis (stage 4S), are prone to spontaneous regression and differentiation (Brodeur \& Bagatell, 2014). In contrast to other cancers, NB is mostly TP53 wild-type tumor (Chen et al, 2010). NB has been recently resolved as a biphasic malignancy with primary tumors containing the cells of adrenergic (ADRN) type, expressing super-enhancer (SE)-associated transcription factors (TFS) GATA3 and PHOX2B, and mesenchymal (MES) type, expressing SE-associated TFS FOSL2 and RUNX2 (Boeva et al, 2017; van Groningen et al, 2017). MYCN amplification (MNA) correlates with ADRN identity (Gartlgruber et al, 2021). Both ADRN and MES lineages produce aggressive metastatic tumors, whereas ADRN identity could be reprogrammed towards a more chemotherapy resistant MES identity. During mouse development, two neural crest derivatives express Phox2b, Gata3, and other markers of ADRN-type sympathoblasts, and the recently identified

\footnotetext{
'Department of Neuroblastoma Genomics, Hopp-Children's Cancer Center at the (NCT) Nationales Centrum für Tumorerkrankungen Heidelberg (KiTZ), Heidelberg, Germany ${ }^{2}$ Department of Neurosurgery, University of Duisburg Essen, Essen, Germany ${ }^{3}$ Center for Medical Genetics, Ghent University, and Cancer Research Institute Ghent, Ghent, Belgium ${ }^{4}$ European Molecular Biology Laboratories, Heidelberg, Germany ${ }^{5}$ Center for Systems Biology, Faculty of Arts and Sciences, Harvard University, Cambridge, MA, USA ${ }^{6}$ Group of Cancer Regulatory Genomics B086, German Cancer Research Center (DKFZ), Heidelberg, Germany ${ }^{7}$ Department of Pediatric Neurooncology, Hopp-Children's Cancer Center at the (NCT) Nationales Centrum für Tumorerkrankungen Heidelberg (KiTZ), Heidelberg, Germany ${ }^{8}$ Department of Immunotechnology, CREATE Health, Faculty of Engineering, Lund University, Lund, Sweden ${ }^{9}$ Institute for Pharmacy and Molecular Biotechnology and BioQuant, Heidelberg University, Heidelberg, Germany ${ }^{10}$ Division of Theoretical Bioinformatics, German Cancer Research Center (DKFZ), Heidelberg, Germany ${ }^{11}$ School of Chemistry and Molecular Biosciences, The University of Queensland, Brisbane, Australia
} 
bridge population that connects Schwann cell precursors and mature chromaffin cells (Furlan et al, 2017). Both of these cell types likely give rise to ADRN lineage. In vitro, ADRN type is represented by neuroblastic $\mathrm{N}$ - and I-type cells, whereas MES type comprises a group of fibroblastlike, substrate adherent S-cells (Walton et al, 2004; Boeva et al, 2017; van Groningen et al, 2017). Differentiation failure in ADRN NB has been traced at the epigenetic, genetic, and transcriptional level and manifests as the down-regulation of the genes involved in maintaining neuronal morphology (Henrich et al, 2016). Yet, many neuritogenesis genes are essential for cell migration and failure in their regulation might be involved in the NB invasion program. The question remains open as to how differentiation block and migratory propensity are balanced in the ADRN lineage's tumors and whether ADRN-type cells are subject to the EMT process. From a point of clinical relevance, the closest compartment that may reflect migration and dormancy, are disseminated tumor cells (DTCS) detected as part of minimal residual disease (Raimondi et al, 2010; Rifatbegovic et al, 2018). Previous studies in NB identified DCX mRNA encoding the core component of neuronal motility, as a robust minimal residual disease marker associated with poor survival in NB patients (Hartomo et al, 2013; Viprey et al, 2014). Based on these facts, we reasoned that understanding the mechanisms implicated in the migration of DCX-positive NB can shed light on the initial steps of the metastatic process in NB. Our data show that $D C X$ expression is associated with ADRN identity. Live-cell imaging reveals that migration in ADRN-type cells is coupled with DCX- and LIS1dependent nucleokinesis (NUC). The silencing or inhibition of RAC1 or ADRN-specific RAC1 guanine nucleotide exchange factor (GEF) KALRN abrogates NUC and, hence, migration. Further analysis with RNAi and chemical compounds reveals kalirin function in coordinating NUC via microtubular (MT) cytoskeleton. These results identify NUC as an important drug target for the development of the migration-specific drug in ADRN-type cells.

\section{Results}

\section{ADRN NB cells migrate nucleokinetically via DCX- and LIS1- dependent mechanism}

We reasoned that, like in neurons, DCX could be part of the migratory program in NB. In primary NB, DCX mRNA correlated positively with mRNAs for ADRN SE-associated TFS, GATA3, and PHOX2B, but not MES FOSL2, suggesting ADRN-specific expression $\left(\mathrm{R}_{\text {GATA3 }}=\right.$ $0.53, R_{P H O X 2 B}=0.51 ; R_{F O S L 2}=-0.09 ;$ Fig S1A). mRNA profiling in NB cell lines, which enabled detection of ADRN-type and MES-type cells (Fig S1B), confirmed this finding and attributed DCX expression to ADRN-type cells (Fig 1A). Chromatin immunoprecipitation sequencing (ChIP-seq) for activation and repression marks demonstrated that $D C X$ was transcribed exclusively in ADRN cell lines, whereas the DCX locus was silenced in MES cell lines, SH-EP and GIME-N (Fig 1B), indicating that ADRN-type cells exclusively express DCX mRNA. An inspection of t-SNE-processed expression data from mouse sympathetic precursors (Furlan et al, 2017) showed that $D c x$ was highly expressed by sympathoblasts (Fig S1C). A lower amount of Dcx mRNA was present in chromaffin cells and the bridge population. In neuroepithelia (NE) and nascent neurons of the central nervous system (CNS), DCX specifically regulates nuclear translocations or NUC (Tsai \& Gleeson, 2005). We reasoned that NUC could affect the ADRN type of NB cells. Live-cell imaging of MNA ADRN cell lines, IMR-32 and NB-S-124 revealed instances of nuclear mobility (Fig 1C). We pursued this observation further by comparing movies of migrating IMR-32 and SH-EP cells expressing histone $\mathrm{H} 2 \mathrm{~B}$ fused to a fluorescent protein (nuclear marker or "_NM") and detected variability in nuclear positioning in migrating TP53wt (Carr et al, 2006) IMR-32 cells, compared with MES-type SH-EP (Fig 1D and Video 1). Next, we recorded positions of cellular (CC) and nuclear centroids (NCS) (CC; NC tracking). Inspection of these tracks revealed NUC events in IMR-32 cells with the nucleus surpassing the cell centroid, followed by cell contraction or the nucleus leapfrogging over the cellular centroid (Fig 1E). We resolved CC; NC tracks (Lan et al, 2016) by linking each NC from a time point $n$ to the CC in a time point $\mathrm{n}+1$, generating $\angle \mathrm{NCn} / \mathrm{NCn}+1 / \mathrm{CCn}+1$ (NNC/NCC) angle distribution and NC-CC maps (Fig 1F, left). This analysis revealed an overrepresentation of $\geq 140^{\circ} ; \leq 180^{\circ}$ block $\left(140-180^{\circ}\right)$, which should reflect leading process (LP) formation, MES mode and posterior NUC, in SH-EP_NM, as well as the overrepresentation of $>0^{\circ} ; \leq 40^{\circ}$ block $\left(0-40^{\circ}\right)$, which should reflect cell contractions and anterior NUC, in IMR-32_NM and SK-N-BE(2)C_NM (TP53mut; Carr et al, 2006) (Fig 1F, left). We decoded NUC events from CC; NC tracks (linkages of the frames: $\left[140-180^{\circ} ; \mathrm{CC}>\mathrm{NN}\right]$, followed by $\left[0-40^{\circ} ; \mathrm{CC}<\mathrm{NN}\right]$; $\left[0-40^{\circ} ; \mathrm{CC}<\mathrm{NN}\right]$, followed by $\left.\left[0-40^{\circ} ; \mathrm{CC}>\mathrm{NN}\right]\right)$ which revealed NUC prevalence in IMR-32_NM and SK-N-BE(2)C_NM, compared with SHEP_NM (Fig 1F, right). Cell velocity in IMR-32_NM and SK-N-BE(2) C_NM cells showed correlation with NUC footprint, compared with SH-EP_NM cells (Fig 1G). To corroborate these findings, we inspected phenotypes of IMR-32, IMR-32_NM, NB-S-124, and three other ADRN cell lines growing on top of three-dimensional collagen (pseudo-3-D assay), and observed traits of neurons migrating through 3-D matrix-bead-like dilations within LPs as well as nuclear deformations (Schaar \& McConnell, 2005; Nishimura et al, 2014) (Fig $1 \mathrm{H}$ and Video 2). Next, we checked the nuclear migration in IMR32_NM after cytochalasin B-induced actin depolymerisation or colcemid-induced MT depolymerisation. Both compounds inhibited cell motility; however, cytochalasin B-treated cells retained mobile nuclei, whereas colcemid treatment prevented nuclear migration (Fig S1D and E and Video 3). These data highlighted the role of MT in NUC in ADRN-type cells. Yet, MT-dependent NUC migration is normally observed in postmitotic cells, which leaves open the question as to how this process blends with the cell cycle in NB. In postmitotic neurons, DCX acts jointly with a dynein regulator LIS1 (PAFAH1B1) (Caspi et al, 2000), whereas in proliferating neural progenitors, DCX and LIS1 function differentially during the process named interkinetic nuclear migration (IKNM) (Carabalona et al, 2016). Two correlative studies have already implicated DCX and LIS1 in NB migration (Messi et al, 2008; Evangelisti et al, 2009), which was in support of their concert action in NB. LIS1 mRNA had a fit with GATA3, PHOX2B, and DCX mRNAs in primary NB $\left(R_{G A T A 3}=0.53, R_{P H O X 2 B}=\right.$ $0.52 ; R_{D C X}=0.42$; Fig S1A). Unlike DCX mRNA, LIS1 mRNA was present in cancers of non-NE origin and MES-type cells (Fig S1F and G), which could reflect LIS1 function during spindle assembly (Moon et al, 2014). Lis1 mRNA did not have an affinity with a particular subgroup in t-SNE-resolved expression data from mouse sympathetic precursors (Furlan et al, 2017; Fig S1C). While IKNM was not 


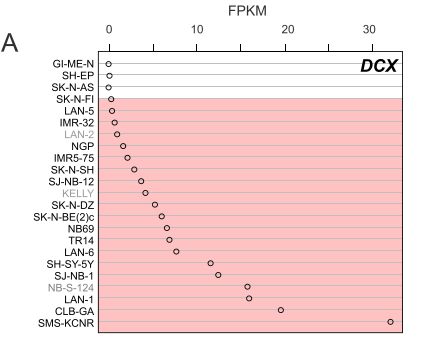

B

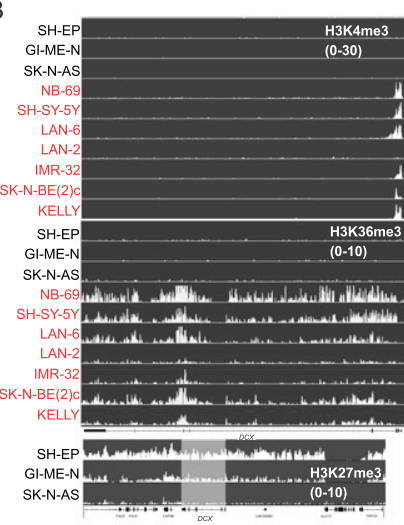

$\mathrm{F}$

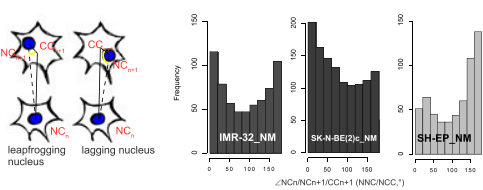

G
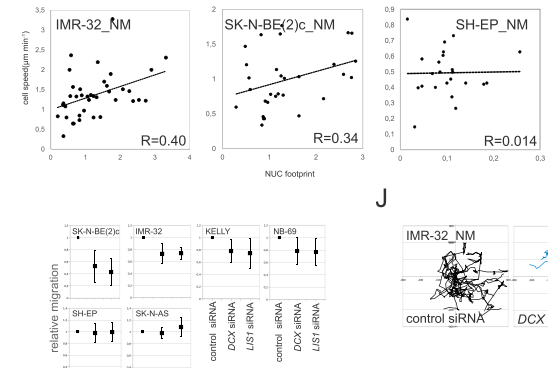

H IMR-32_NM

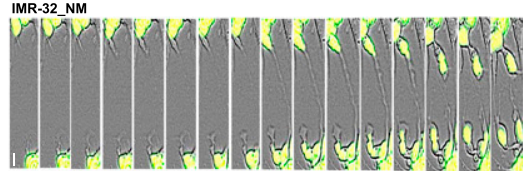

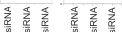

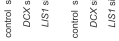

$\mathrm{K}$
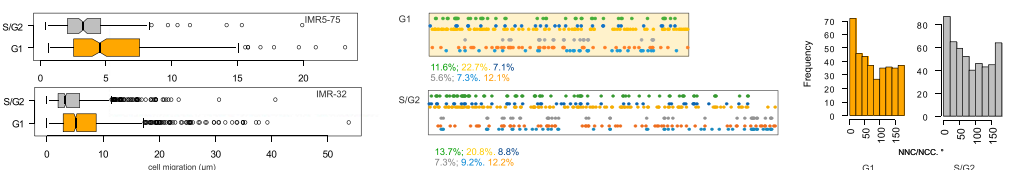

$\mathrm{L}$

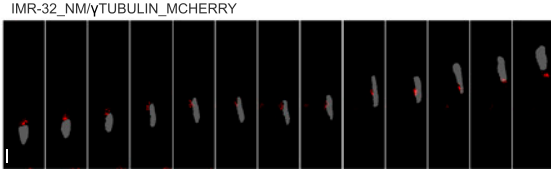

Figure 1. NB cells exhibit NUC during migration. (A) DCX mRNA expression in MES and ADRN (marked in red) cell lines (the names of ADRN cell lines whose identity was assigned based on the phenotype and/or PHOX2b, GATA3, and FOSL2 transcription are represented in grey color [Fig S1A], the cell type identity in the other cell lines [black color] is described in the literature). (B) ChIP-seq showing $\mathrm{H} 3 \mathrm{~K} 4 \mathrm{me} 3, \mathrm{H} 3 \mathrm{~K} 36 \mathrm{me} 3$, and H3K27me3 binding at the DCX locus in three MES and ADRN (marked in red) cell lines. For H3K27me3 binding, the region surrounding $D C X$ locus (white box) was visualized in IGV program. (C) Time-lapse images showing migrating NB-S-124 and IMR-32 cells. (D) Time-lapse images of IMR-32_NM and SHEP_NM cells during migration. Nuclear (in blue) and cellular center (in orange) of migrating cells are indicated. Scale bar $20 \mu \mathrm{m}$. (E) CN trajectories and $\mathrm{CN}$ plots of representative IMR-32_NM and SHEP_NM cells. (F) Schematic of nuclei positioning determined by $\mathrm{NCn}+1-\mathrm{NCn} / \mathrm{NCn}+1-\mathrm{CC}+1$ angle (NNC/NCC) (left) and NNC/NCC angle frequency distribution in IMR-32 NM, SK-N-BE(2)C NM, and SH-EP_NM cells (right). NUC events decoded from CC; nuclear centroid tracks in concatenated tracks from IMR-32_NM, SK-N-BE(2)C_NM, and SHEP_NM (top right). Mapping of NUC (exemplary track in red), positive and negative noise-corrected NC-CC distances, $0-40^{\circ}$ and $130-180^{\circ}$ signatures (two or more sequential frames within the same angle block) (exemplary multi-colored track) in concatenated tracks from IMR-32_NM, SK-N-BE(2) C_NM and SH-EP_NM (bottom right). (G) Correlation plots between cell velocity and NUC footprint (weighted mean NUC distance) in IMR-32 NM, SK$\mathrm{N}-\mathrm{BE}(2)$ C_NM and SH-EP_NM cells. (H) Live imaging of pseudo-3-D-assayed IMR-32 NM cells. Scale bar $10 \mu \mathrm{m}$. (I) 2D exclusion assay in NB cell lines after RNAi against DCX or LIS1 $72 \mathrm{~h}$ post-transfection. Relative cell migration is quantified by cell density's normalization to control siRNA-transfected control. Graphs represent the mean relative difference migration \pm SD. (J) Random walk plots and accumulated migration distances in control IMR32_NM cells and after RNAi against DCX or LIS1 $72 \mathrm{~h}$ post-transfection (13 h, 15-min intervals). Mean migration distances + SD are presented. (K) Box plots showing cell migration distances in 216 and 1,528 (G1 phase), 167 and 985 (S/G2 phases) sequential timepoints (20 and 5 min per timepoint, respectively) from tracings of 13 cells from IMR5-75 and 22 cells from IMR-32 expressing the G1 cell cycle sensor (left); P-values: IMR5-75: $6.168 \times 10^{-5}$, IMR-32: $2.2 \times 10^{-16}$ (two-sample Kolmogorov-Smirnov test). NNC/NCC angle frequency distribution and noise-corrected nuclear centroid-CC distances (right) in $0-40^{\circ}$ and $140-180^{\circ}$ signatures in concatenated tracks from IMR-32_NM expressing the G1 cell cycle sensor. (L) Time-lapse images showing representative migrating IMR-32_NM expressing $y$-tubulin. Scale bar $20 \mu \mathrm{m}$. amenable to examination in dissociated cultures because of the absence of adherens junctions present in vivo (LaMonica et al, 2013), differential knockdown (KD) of DCX, controlling G1-specific, kinesin-dependent NUC (Carabalona et al, 2016), and of LIS1, controlling G2-specific, dynein-dependent NUC, and spindle assembly during IKNM (Tsai et al, 2005; Yingling et al, 2008; Carabalona et al, 2016), could help to tell IKNM from NUC in NB. 2D exclusion assays revealed inhibition of migration after either $D C X$ 
or LIS1 KD in ADRN cell lines (Fig 11). Proliferation in NB cell lines was not affected in DCX-KD and LIS1-KD cells (Fig S1H), which ruled out DCX and LIS1 involvement in spindle assembly or cell cycle transition in NB. Our tracking of randomly walking cells in $D C X-K D$ and LIS1-KD IMR-32_NM spheroids showed inhibition of motility (Fig 1) and Video 4; data not shown). We then tested cell cycle specificity of migration in ADRN-type cells by performing cell tracking in asynchronously growing IMR-32 and an IMR-32 derivate, IMR5-75 expressing a FUCCI cell cycle sensor (Ryl et al, 2017), which revealed a tendency for migration in $\mathrm{G} 1$ phase (Fig 1K, left). No significant difference in NNC/NCC angle distributions in G1 and S/G2 phases was observed in IMR-32_NM (Fig 1K, right). Expression of a construct encoding $\gamma$-tubulin fused to mCherry in IMR-32 showed that nuclei surpassed $y$-tubulin signals during migration (Fig $1 \mathrm{~L}$ and Video 5), which was in agreement with the nucleuscentrosome (N-C) inversion mechanism (Umeshima et al, 2007).

The plotting of nuclear positions ( $\mathrm{NCn}-\mathrm{CCn}$ or $|\mathrm{NC}-\mathrm{CC}|$ ) showed that nuclei were less present in the periphery of the cells after $D C X$ or LIS1-KD (Fig 2A). Staining for NUC-relevant neuronal $\beta$ III-tubulin (Xie et al, 2003) and $\gamma$-tubulin showed that cell phenotypes produced by RNAi of DCX and LIS1 were different and resembled neurons after Lis1 or DCX-KD (Youn et al, 2009; Nishimura et al, 2014), that is, higher variability in the $\mathrm{N}-\mathrm{C}$ distance and dose-dependent unipolar neurite outgrowth in LIS1-KD cells as well as defective LPS in DCX-KD cells (Fig 2B). Accordingly, suppression of $0-40^{\circ}$ signature, NUC as well as no NNC/NCC angle overrepresentations were seen after DCX-KD and LIS1-KD, respectively (Fig $2 C$ and D). Yet, cell velocity in DCX-KD and LIS1-KD IMR-32_NM cells showed substantial correlation with the NUC footprint (Fig 2E). Altogether, these analyses showed no evidence for MES migration mode in LIS1-KD and $D C X-K D$ IMR-32_NM cells. Also, gene set enrichment analysis (GSEA) of DCX- and LIS1-KD IMR-32 RNA-seq-resolved expression profiles showed that there was no induction of the MES program (Fig S2A and Table S1), which supported our idea regarding the maintenance of ADRN program after DCX- and LIS1 RNAi. DCX-KD and LIS1-KD transcriptomic profiles showed remarkable overlap (Fig 2F). Particularly, MT-related gene signatures and gene signatures associated with cortical cytoarchitecture were depleted in DCX-KD and LIS1-KD transcriptomes (Table S1). Gene signatures related to nonsense-mediated decay (NMD) and mRNA transport, mitochondrial function, oxidative phosphorylation (oxphos) signature, as well as genes related to cell contraction and Ras signalling regulation were specifically depleted in DCX-KD and LIS1-KD cells, respectively (Figs $2 \mathrm{G}$ and $\mathrm{S} 2 \mathrm{~B}$ ). The down-regulation of pathways related to mitochondrial function was the only expression trait shared with KD of a DCL family gene, dclk1 in mouse neuroblastoma (Verissimo et al, 2010) (Table S1). On the other hand, GSEA of the up-regulated genes showed less consistency even under the relaxed threshold ( $q$ values $\leq 0.25$ ) (Table S1). Pseudogene transcripts, signatures related to G-protein coupled receptor signalling and PTPRB neighbourhood were overrepresented by the up-regulated genes in $D C X$ KD cells (Fig S2C and Table S1). Next, we assessed DCX- and LIS1-KD expression profiles in the context of primary NB using three clinically relevant dichotomies (stage $4 S$ versus stage 4 , stages $1 / 2$ versus stage 4; MYCN-nonamplified versus MNA tumors). This analysis showed that up-regulated, but not down-regulated genes in the $D C X-K D$ cells had an affinity toward transcriptomic profiles of stage
4S, stages $1 / 2$ and MYCN-nonamplified tumors (Figs $2 \mathrm{H}$ and S2D). We then extracted then the genes from DCX- and LIS1-KD profiles that did not recapitulate association with low-risk characteristics, which we named "mis-expressed" genes (DCX(LIS1)-KD UP $\cap$ stage 4S [stages 1|2;

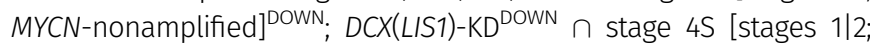
MYCN-nonamplified] ${ }^{\mathrm{UP}}$ [P-values $\leq 0.05$, no logFC threshold]). GSEA showed that mis-down-regulation engaged TP53 targets and mis-upregulation engaged CHEK2 neighbourhood in LIS1-KD cells (Fig 21 and Table S1). Given the association of LIS1 expression with favourable prognosis in NB (Garcia et al, 2012), these results might reflect LIS1 involvement in the potentially tumor-suppressive process(es) in NB. In $D C X-K D$ cells, little consistency was found in the list of mis-upregulated genes, whereas mis-down-regulation engaged genes encoding extracellular matrix, MYC targets as well as genes marked bivalently in the CNS (Fig 2J). These observations showed that phenotypic NUC inhibition in ADRN-type NB could generate disparate transcriptomic alterations. In DCX-KD cells, the down-regulated genes showed positional enrichment for NB-relevant regions of loss of heterozygosity (Mora et al, 2001; White et al, 2001; Lasorsa et al, 2020), including 19p13, 19q13, and 1p36 (Table S1). We checked the literature on NB for similar observations and found that a link between MYCN down-regulation and oxphos inhibition was identified previously in MNA NB cells (Dzieran et al, 2018; Oliynyk et al, 2019). Also, the positional depletion of 19p13 genes was observed in disseminated NB tumor cells (NB DTC) from relapsed patients (Table S8 by Rifatbegovic et al, 2018). Although the 19p13 gene overlap in the DCX-KD and NB DTC profiles was negligible (Table S1), 19p13 shutdown in relapse DTCS and DCX-KD cells could imply similar regulatory mechanisms. We retrieved the RNA-seq data from NB DTCs and reanalysed with the following settings: no logFC cutoff; $P$-values $\leq$ 0.05; DTC ${ }^{\text {TOTAL }}$ versus Tumor (TU) ${ }^{\text {TOTAL }}$; DTC $^{\text {MNA }}$ versus TU ${ }^{\text {MNA; }}$ DTC RELAPSE versus TU ${ }^{\text {RELAPSE }}$ to identify whether similarities between transcriptomic profiles of DCX-KD IMR-32 and NB DTC go beyond the 19p13 genes. DCX-KD UP gene set showed splitting when mapped onto NB DTC transcriptome profiles, whereas $D C X$ KD DOWN showed a match with NB_DTC DOWN (Fig 2K). Cross-checking for immune cell-specific signatures showed that the presence of $D C X$ KD ${ }^{\mathrm{UP}} \cap$ NB_DTC ${ }^{\mathrm{UP}}$ overlap could not be explained by bone marrow cell contamination (Fig S2E). Several gene signatures associated with stage 4S, stages $1 / 2$ and MYCN-nonamplified status, as identified by the parametric analysis of gene set enrichment (PAGE analysis) using gse49710 signature (Table S1), showed similar splitting (Fig S2F), suggesting cellular heterogeneity of NB DTCS rather than a gene signature functional variegation.

Altogether, the results show that migration in ADRN-type cells depends on the $\mathrm{N}-\mathrm{C}$ inversion mode of NUC that requires both DCX and LIS1, which rules out the possibility of proliferative NUC, IKNM. The results also imply that $D C X-K D$-like situations appear in disseminated NB cells.

\section{ADRN SE-associated TF, SOX11, is involved in NUC regulation in ADRN NB}

The parallelism between migration modes in neurons and ADRNtype NB cells is likely to extend to the transcription control, which could involve neuron-specific TFs embedded in NB pathogenesis. We reasoned that $D C X$ co-expression signature may shed information on NUC control in NB, as the expression of DCX mRNA was a specific trait of cancers of NE origin, including NB (Figs 3A, top and 
A

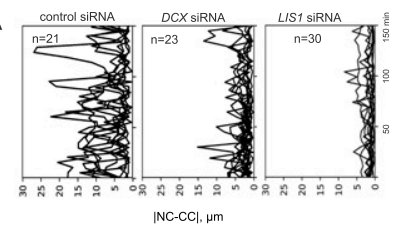

C

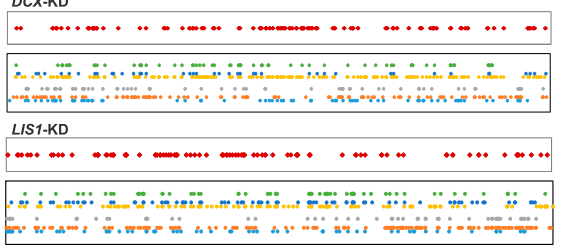

D

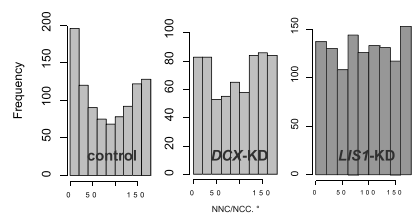

G

$\mathrm{F}$

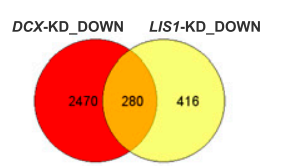

DCX-KD_UP LIS1-KD_UP

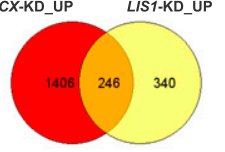

B

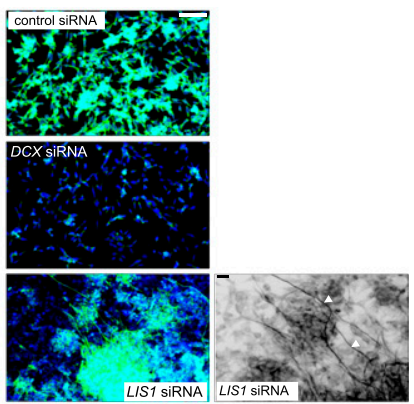

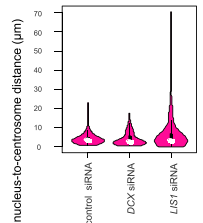

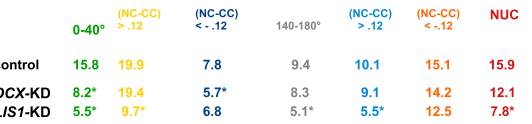

E

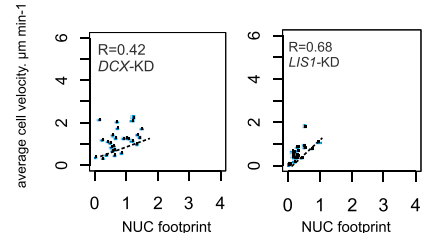

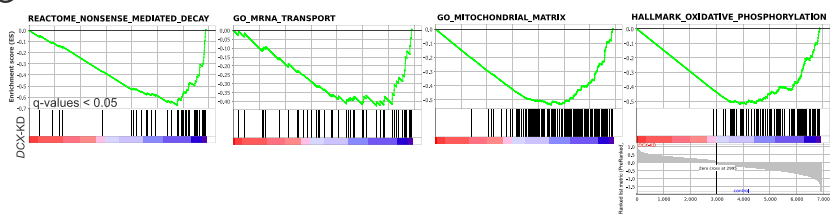

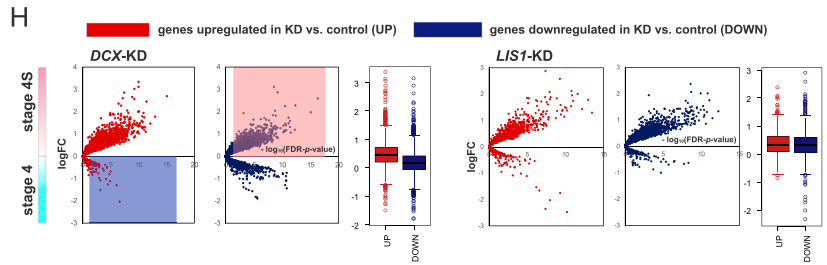

Figure 2. NUC genes are involved in migration in ADRN-type cells.

(A) $|\mathrm{NC}-\mathrm{CC}|$ plots for control IMR-32_NM cells and the cells after DCX- or LIS1-KD $72 \mathrm{~h}$ post-transfection.

(B) $\beta$ III-tubulin immunolabeling (top left) in control IMR-32 cells and after RNAi against DCX and LIS1 $72 \mathrm{~h}$ post-transfection. Neurite outgrowth after LIS1 RNAi (bottom left; grayscale negative field) is indicated by white arrows. Scale bar $100 \mu \mathrm{m}$. Violin plots showing the nucleus-to-centrosome distance distribution in $D C X$ - and LIS1-KD IMR-32 cells (right). Means are indicated. P-values: DCX siRNA: 0.009898, LIS1 siRNA n.s.; (Welch $t$ test). (C) Mapping of NUC, positive and negative noise-corrected $\mathrm{NC}-\mathrm{CC}$ distances, $0-40^{\circ}$ and $140-180^{\circ}$ signatures in concatenated tracks from DCX-KD (27 cells, 762 time points) and LIS1-KD (41 cells, 1,256 timepoints) IMR-32_NM. (D) NNC/NCC angle frequency distribution in concatenated tracks in $D C X$ and LIS1-KD IMR-32_NM cells. (E) Correlation plots between cell velocity and NUC footprint in DCX-and LIS1-KD IMR-32_NM cells. (F) Venn diagram showing overlaps between the differentially expressed genes (DEGs; | logFCI cutoff: 0.3) in DCX- and LIS1-KD IMR-32 versus control IMR-32. (G) Gene set enrichment analysis plots of the indicated gene sets in DCX-KD IMR32. False discovery rate (FDR)-adjusted $P$-values (qvalues) are listed. (H) Volcano plots showing log2 $\mathrm{FC}$ expression (y-axis) and log10 FDR-adjusted $P$-value $(-\log 10$ FDR- $P$-value, $x$-axis) of DEGs in DCX- and LIS1-KD IMR-32 in stage $4 S$ versus stage 4 tumors (GEO: gse49710). Each dot represents an individual spot. (I, J) Gene set enrichment analysis plots of the indicated gene sets in LIS1- and DCX-KD IMR-32 based on their mis-expression in stage $4 \mathrm{~S}$ versus stage 4 tumors ( $P$ values by two-way $t$ test $\leq 0.05$, no $\log F C$ cutoff). (K) Plots showing mapping of DEGS of DCX-KD IMR-32 onto NB disseminated tumor cell transcriptome profiles (Rifatbegovic et al, 2018).
I

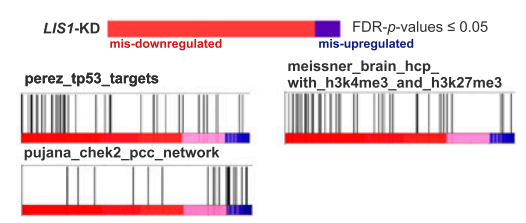

$J$

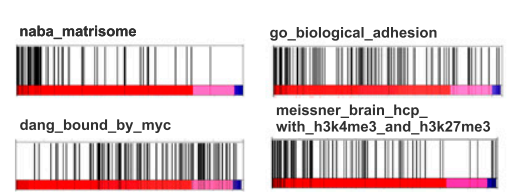

K

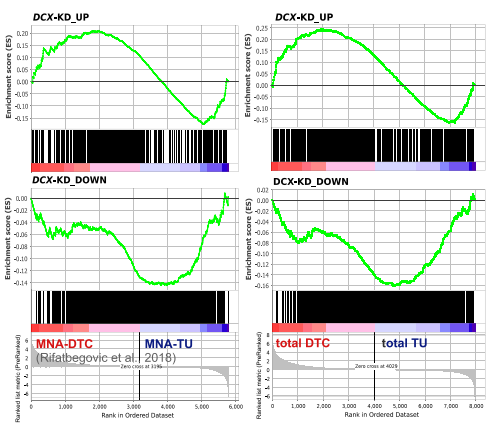


A

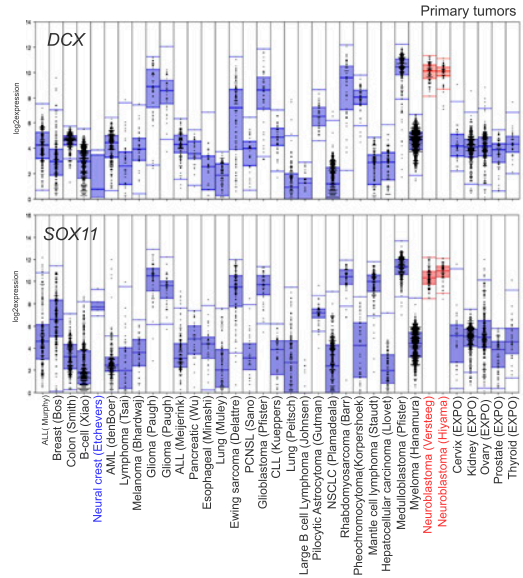

C
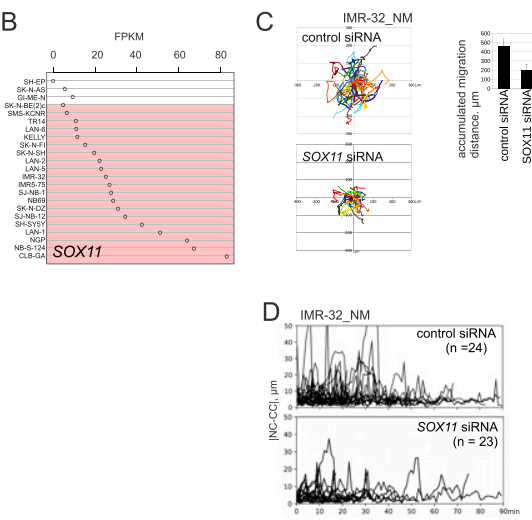

$E$

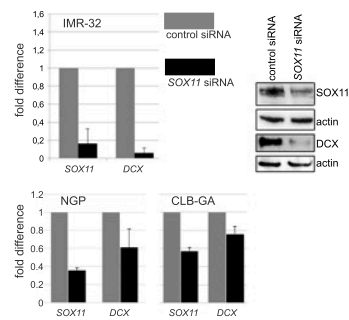

$\mathrm{F}$

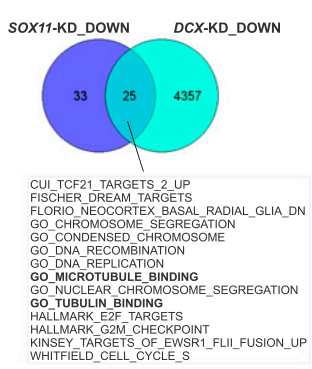

$G$

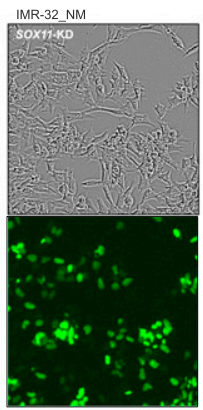

J
$\mathrm{H}$
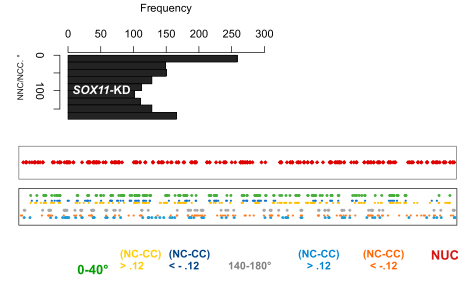

$\begin{array}{llllllll}\text { control } & 15.4 & 18.1 & 9.4 & 10.2 & 8.5 & 16.7 & 14.9\end{array}$

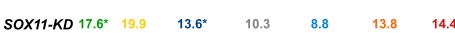

I

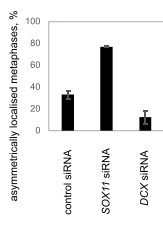

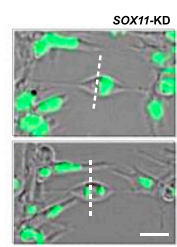
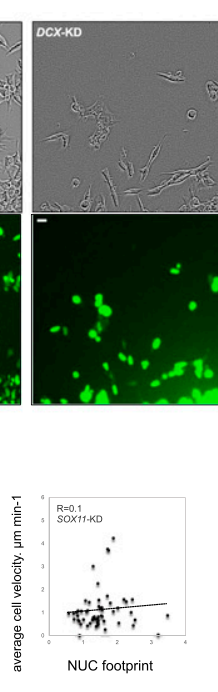

Figure 3. SoX11 regulates NUC.

(A) Affymetrix DCX mRNA (probe set 229349, top) and SOX11 mRNA (probe set 204914, bottom) expression analysis from primary tumors. (B) SOX11 mRNA expression in MES and ADRN (marked in red) cell lines. (C) Random walk plots and accumulated migration distances in control IMR32_NM and after RNAi against SOX11 $72 \mathrm{~h}$ posttransfection (6 h, 15-min intervals). Mean migration distances + SD are presented. The efficiency of SOX11-KD was determined by WB. (D) Representative |NC-CC| plots in IMR-32 NM controls and after RNAi against SOX11. (E) Relative qRT-PCR for SOX11 and DCX in IMR-32 after SOX11 RNAi $72 \mathrm{~h}$ post-transfection and in NGP and CLBGA after SOX11 RNAi 48 h post-transfection (left). Mean relative difference values + SE of control are presented. WB for DCX in IMR-32 after $48 \mathrm{~h}$ post-transfection (right). (F) Venn diagram showing the number of gene sets (extracted from MSigDB [22,596 gene sets]) in IMR-32 DCX-KD ${ }^{\text {DOWN }} \cap$ SOX11KD ${ }^{\text {DOWN }}$ semantic overlap ( $q$-values $\leq 0.05$ ). (G) Cell morphology in SOX11-and DCX-KD cells. Scale bar $20 \mu \mathrm{m}$. (H) NNC/NCC angle frequency distribution (top) and mapping of NUC, positive and negative noise-corrected NC-CC distances, $0-40^{\circ}$ and $140-180^{\circ}$ signatures (bottom) in SOX11KD (57 cells, 1,314 timepoints). (I) The percentages of asymmetrically localised metaphases (left) in control, SOX11- and DCX-KD IMR-32_NM. Mean percentages + SD are presented. Representative images of dividing SOX11-KD cell (right, scale bar $20 \mu \mathrm{m})$. (J) Correlation plot between cell velocity and NUC footprint (weighted mean NUC distance) in SOX11-KD IMR-32_NM. (K) Gene set enrichment analysis plots showing gene sets "wound healing" and "epithelial-mesenchymal transition" in SOX11$\mathrm{KD}$ versus control. (L) Venn diagram showing the number of gene sets (MSigDB) in IMR-32 SOX11$\mathrm{KD}^{\mathrm{UP}} \cap D C X-\mathrm{KD}^{\mathrm{DOWN}}$ semantic overlap (q-values $\leq$ 0.05). (M) Volcano plots showing expression of DEGs in SOX11-KD IMR-32 in stage 4S versus stage 4 tumors.
$\mathrm{K}$

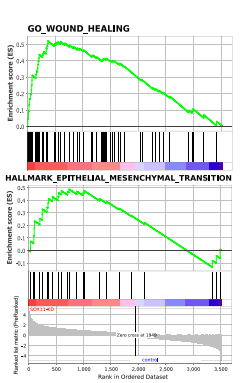

$\mathrm{L}$

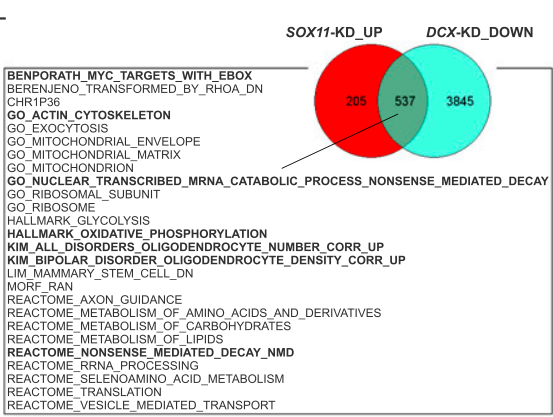

M

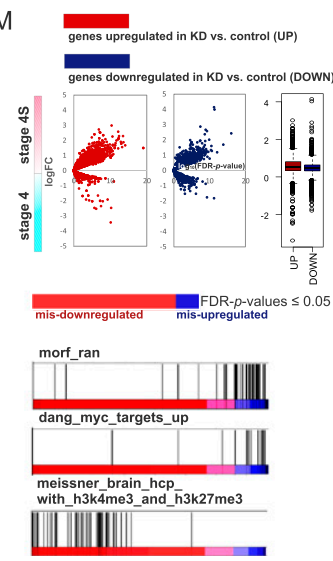

mRNA-correlated TF in stage 4; $\left.R_{\text {stage } 4}=0.54\right)$. SOX11 is mutated in Coffin-Siris syndrome (Tsurusaki et al, 2014; Nemani et al, 2014) and is a likely candidate for 2 p25.2 deletion syndrome (Lo-Castro et al, 2009); these disorders are characterised by microcephaly with hindbrain abnormalities. In mice, Sox11 deficiency generates complex CNS defects that stem from proliferation deficits in NE and neuronal migration errors (Hoshiba et al, 2016). In peripheral nervous system (PNS), Sox11 regulates proliferation during 
the early development of sympathetic ganglia (Potzner et al, 2010). It was previously shown that Sox 11 was indispensable for the proliferation of tyrosine hydroxylase-expressing precursors in developing sympathetic ganglia (Potzner et al, 2010). In line with this, Sox11 expression was observed in sympathoblasts and the bridge population (Furlan et al, 2017; Fig S3D). In NB, SOX11, identified previously as an SE-associated TF in ADRN-type cells (van Groningen et al, 2017), was highly expressed in MYCN-nonamplified stage 4 and MNA NB (localised [LOC] versus MYCN-nonamplified stage 4, $P$-value $<0.005$; MYCN-nonamplified versus MNA, $P$-value < 0.001; one-way ANOVA test; Fig S3E). SOX11 expression profile across cancer cell lines and primary tumors showed concordance with DCX expression, except for human neural crest cells and pheochromocytoma, which could partially reflect earlier SOX11 induction during neural crest development and SOX11 lineage specificity (Potzner et al, 2010; Figs 3A, bottom and S3F). Consistently, SOX11 mRNA was prevalent in ADRN cell lines, as compared with MES cell lines (Fig 3B). SOX11 directly controls DCX expression in neurons (Mu et al, 2012), which could also hold true in NB and, hence, affect cell migration. We observed decreased migration from SOX11-KD IMR-32_NM spheroids and the closure of $|\mathrm{NC}-\mathrm{CC}|$ distance along with $D C X$ downmodulation (Fig 3C-E and Video 4). Real-time GRT-PCR in two other SOX11 high expressors, ADRN cell lines CLB-GA and NGP, also showed DCX mRNA depletion after SOX11 RNAi (Fig 3E). As RNA-seq data showed, SOX11 targets identified in mouse ES-derived nascent neurons (Bergsland et al, 2011) were significantly down-regulated (q-value < 0.05), whereas other SOX11 target datasets (Lachmann et al, 2010; Kuo et al, 2015) did not demonstrate depletion (Fig S3G). DCX- and SOX11-KD transcriptomic profiles showed little overlap, but formed a $D C X$ $K^{\text {DOWN }} \cap$ SOX11-KD DOWN semantic match that involved signatures related to MT function and mRNA transport as well as MYC targets (Fig 3F). No overlapping signatures were found in the up-regulated genes (Table S2). In contrast to the findings in neurons (Piens et al, 2010; Mu et al, 2012), DCX promoter was not bound by SOX11 in NB cells (Decaesteker et al, 2020 Preprint). Also, SOX11-KD IMR32_NM had different morphology, as compared with the DCX-KD cells (Fig 3G) and retained parental NNC/NCC angle distribution (Fig 3H, top). The impact of $0-40^{\circ}$ signature and $0-40^{\circ}$-linked NUC was preserved in SOX11-KD cells (Fig 3H, bottom). Given the intact NNC/ NCC angle distribution, it was worth checking nuclei localisation in the pre-mitotic KD cells, which revealed a higher percentage of asymmetrically localised metaphases in SOX11-KD IMR-32_NM, compared with $D C X-K D$ and control cells (Fig 3I). Cell velocity in SOX11-KD IMR-32_NM cells showed no correlation with NUC footprint, compared with control or NUC-suppressed, DCX-KD and LIS1-KD cells (Figs 3J and 2E). This suggested that SOX11-KD IMR-32_NM acquired slower, NUC-independent migration mode. In line with this, we observed the overrepresentation of gene hallmarks "wound healing" and "EMT" by the up-regulated genes, which supported our idea about SOX11 RNAi-induced reprogramming (Fig 3K and Table S2). SOX11 RNAi resulted in down-regulation of several ADRN TFS, ISL1, KLF7, MYCN, and neuron-specific RNA binding protein-encoding ELAVL2 and ELAVL4, as well as induction of MES TFS, ETS1 and JUND (Boeva et al, 2017; van Groningen et al, 2017; Zeid et al, 2018) (Table S2) and the targets of ETS-1 and AP-1. The targets of ELAVL proteins identified previously in IMR-32 (Scheckel et al, 2016) were down-regulated in SOX11-KD IMR-32, which was in striking contrast to the DCX-KD profile (Fig S3H). Also, gene signatures "oxphos," "NMD" and gene lists associated with migration/actin cytoskeleton regulation and cortical cytoarchitecture showed inverted pattern of regulation in SOX11-versus DCX-KD cells (SOX11-KD ${ }^{\mathrm{UP}} \cap \mathrm{DCX}$ $\mathrm{KD}^{\mathrm{DOWN}}$ ) (Fig 3L and Table S2). Further assessment of SOX11-KD transcriptomic profile in the context of the clinically relevant dichotomies revealed that mis-up-regulation engaged MYC targets, RAN neighbourhood, whereas mis-down-regulated involved bivalently marked genes (Figs 3M and S3I and Table S2). The SOX11KD ${ }^{\text {DOWN }}$ gene set matched with NB DTC UP set (Fig S3J). This indicated that SOX $11^{\mathrm{HIGH}}$, rather than SOX11 ${ }^{\text {LOW }}$ IMR-32 reflected a NB DTC subcompartment. Next, we inspected whether SOX11 was capable of initiating the MES-to-NUC transition by forcibly expressing SOX11 in the inducible format in SH-EP. We observed a moderate velocity gain in the cells with enforced SOX11 expression, compared with the controls (Fig S3K). NNC/NCC angle distribution revealed acquisition of $0-40^{\circ}$ block in SH-EP expressing SOX11, but the highest cell velocity was associated with $140-180^{\circ}$ block in SH-EP expressing SOX11 (Fig S3L), suggesting that SOX11 forced expression interfered with nuclear positioning mechanisms in SH-EP without reprogramming migration type.

Altogether, these data show that NUC is controlled by SOX11 in NB. SOX11 RNAi fosters morphological asymmetric cell divisions and causes reprogramming of NUC migration in ADRN-type NB cells. The latter was in contrast to the observations carried out in nascent neurons previously.

\section{Inhibition of ROCK or RAC1 blocks different steps of NUC migration}

We reasoned that targeting the intrinsic regulators of the MT cytoskeleton to generate DCX RNAi-like NUC errors was a prospective direction for the development of migration blockers in the ADRN-type NB. In neurons, the formation of LPs is regulated by RAC1, whereas actomyosin contractions at the trailing end are regulated by RHOA-ROCK (Kawauchi et al, 2003; Martini \& Valdeolmillos, 2010). The down-regulation of RAC1 neighbourhood, RHOA-related gene signatures, "BERENJENO_transformed_ by_RHOA_DN," and "BERENJENO_transformed_by_RHOA_UP," after DCX RNAi indirectly supported the role of the RAC1 and RHOA pathways in DCX-KD phenotype in NB (Fig 4A). To assess these processes, we applied a ROCK inhibitor, Y27632 (5 $\mu \mathrm{M})$, which reduced migration in all tested ADRN and MES cells, whereas cell viability was unaffected (Figs 4B, left and S4A and B). In contrast, an RAC1 inhibitor, NSC23766 (10 $\mu \mathrm{M})$ (Bid et al, 2013), reduced migration only in ADRN cell lines without affecting cell viability (Figs 4B, left and $S 4 B$ and $C$ ), in line with the observed effect upon RAC1 siRNA treatment (Figs 4B, right and S4D). In neurons, the RAC1 function is mainly associated with the modulation of cytoskeletal dynamics in the growth cones, dendritic spines, and lamellipodia, which are absent in IMR-32 (Fig S4E, left). In line with this, per equal amount of total protein, basal RAC1 activity was lower in ADRN IMR-32 and SK$\mathrm{N}-\mathrm{BE} 2 \mathrm{C}$, as compared with SH-EP (Fig S4E, right). The absence of lamellipodia was reflected by perinuclear and nuclear localisation of RAC1 identified with either immunostaining in IMR-32 or forced expression of fluorescent protein-tagged full-length RAC1 (Fig 4C). Visually, only ROCK inhibitor-exposed ADRN-type cells underwent a 
A

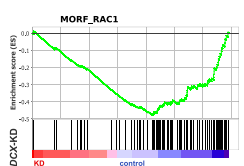

B

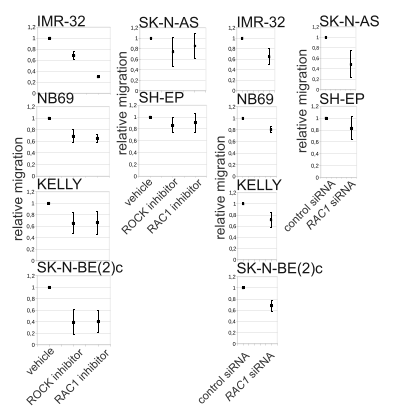

D

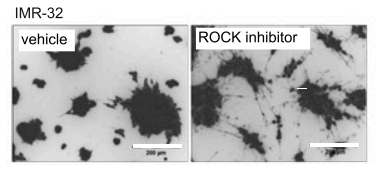

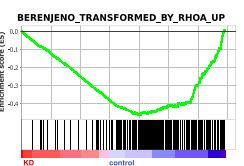

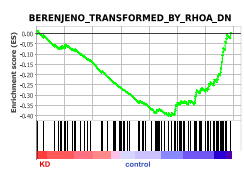

C
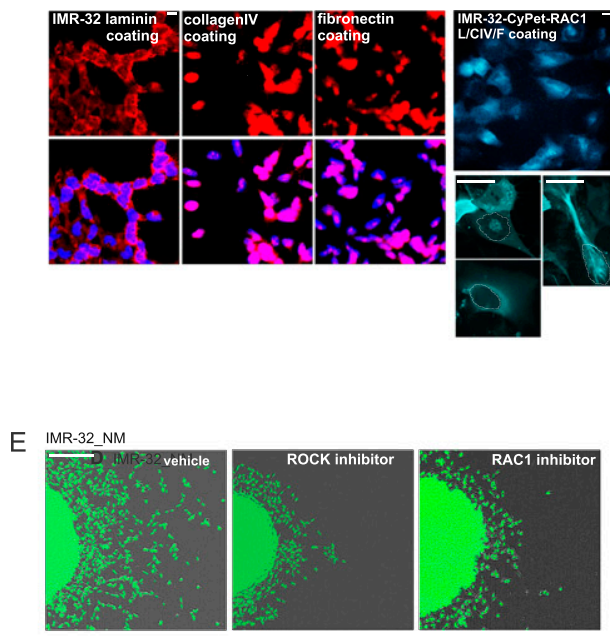

$\mathrm{F}$

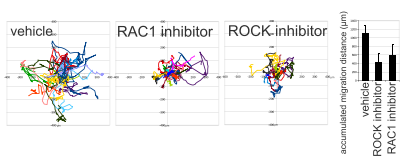

G

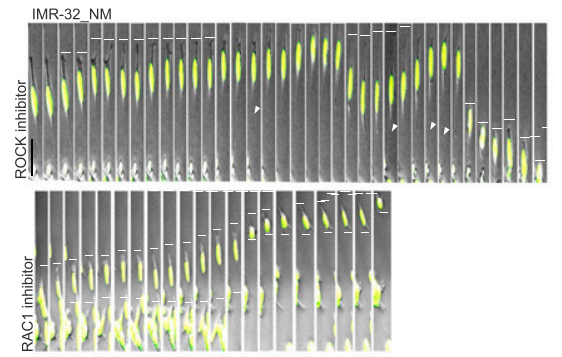

$\mathrm{H}$

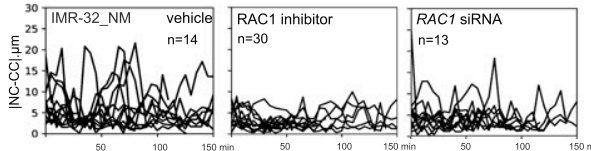

।

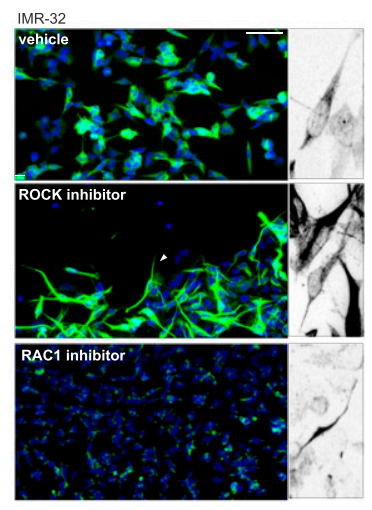

Figure 4. ROCK and RAC1 inhibition interferes with cell detachment and NUC.

(A) Gene set enrichment analysis plots showing RHOArelated and RAC1-related gene sets in DCX-KD IMR-32 versus control. (B) $2 \mathrm{D}$ exclusion assay in NB cell lines after treatment with the RAC1 inhibitor or ROCK inhibitor and after RAC1 RNAi (left). Relative cell migration (right) is quantified by normalization of cell density to vehicle- or control siRNA-treated cells. Mean relative difference values $\pm S D$ are presented. (C) RAC1 immunostaining and CyPet-RAC1

subcellular localisation in IMR-32 (L, laminin; CIV, collagen IV; F, fibronectin). Scale bar $20 \mu \mathrm{m}$. (D) Images of IMR-32 spheroids stained with Calcein AM after 72 $h$ of treatment with vehicle or ROCK inhibitor in pseudo 3-D. (E) Random walk plots in IMR-32_NM treated with vehicle, RAC1 inhibitor or ROCK inhibitor for $72 \mathrm{~h}$ (13 h, 15-min intervals). Scale bar $200 \mu \mathrm{m}$. (F) Accumulated migration distances of control, ROCK inhibitor- and RAC1 inhibitor-treated IMR-32_NM cells and after ROCK1, ROCK2, or RAC1 RNAi. Mean migration distances + SD are presented. (G) Time-lapse images of IMR-32_NM after treatment with ROCK inhibitor (left) or RAC1 inhibitor (right). Nuclei and cell leading edges of migrating cells are indicated. Scale bar $20 \mu \mathrm{m}$. (H) $|\mathrm{NC}-\mathrm{CC}|$ plots in control IMR-32_NM and after treatment with the RAC1 inhibitor or RNAi against RAC1. (I) BIII-tubulin immunolabeling in IMR-32 after treatment with vehicle, ROCK- or RAC1 inhibitor. Fork-like structures are showed in grayscale negative field. Scale bar $100 \mu \mathrm{m}$. (J) Venn diagrams showing the numbers of genes in $D C X-K D \cap$ RAC1 inhibitor transcriptomic overlap ( $P$-values $\leq 0.09 ;|\log F C|$ cutoff [DCX-KD]: 0.3, |logFC| cutoff [RAC1 inhibitor]: 0.2). (K) Volcano plots showing expression of DEGs in RAC1inhibitor-treated IMR-32 in stage 4 S versus 4 tumors.
$J$

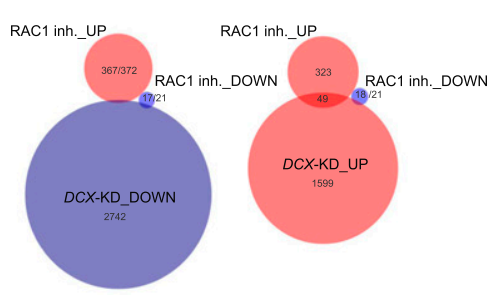

K

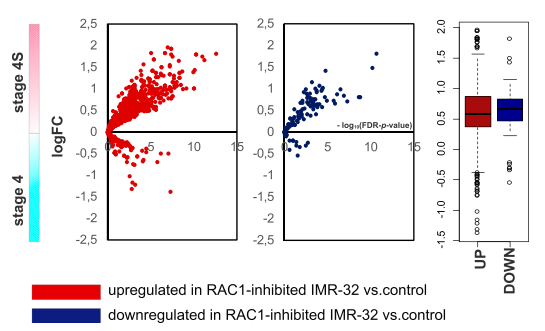

profound morphological transformation (Figs 4D and S4F). Tracking showed motility defects after either RAC1 or ROCK inhibition in IMR32_NM, which was further confirmed by RNAi against ROCK1, ROCK2, and RAC1 (Figs $4 \mathrm{E}$ and F, and S4G and Video 5). Both RAC1- and ROCK inhibition-induced defects in IMR-32_NM fit the neuroblastic cell phenotype and did not demonstrate MES traits (Fig $4 \mathrm{G}$ and Videos 5-Videos 7). Cell morphology after RAC1 suppression revealed NUC defects, which was also confirmed by the results of |NC-CC| plotting 
(Fig 4H). In agreement with RAC1/ROCK antagonism (Petrie et al, 2009), RAC1 inhibitor-treated cells maintained cell contractions, whereas ROCK inhibitor-exposed cells retained nuclear migrations but failed to detach (Fig S4H and Videos 5-Videos 7). Staining for $\beta$ III-tubulin revealed that ROCK inhibition up-regulated NUC fork-like MT elements (Xie et al, 2003), whereas fewer MT structures were observed after RAC1 inhibition, which was an indication of RAC1 involvement in the regulation of NUC MTS (Fig 4I). RNA-seq analysis showed that there was an overlap between transcriptomic alterations induced by RAC1 inhibitor and DCX-KD (Fig 4)). Similar to DCX RNAi, genes up-regulated by RAC1 inhibition genes had an affinity towards stage $4 S$, stages $1 / 2$ and MYCN-nonamplified status (Figs 4K and S4I). GSEA showed that the genes up-regulated by RAC1 inhibition were enriched for TCF21-dependent genes and bivalently marked genes (Table S3). Although we did not find GSEA-based evidence for MES signature in the transcriptomic profile of RAC1inhibited cells, several hallmarks, including ETS fusion (EWS/ETS) targets, formed an overlap with the SOX11-KD UP gene set. Also, RAC1 neighbourhood genes that showed inverted, DCX-KD DOWN/SOX11$K D^{U P}$, expression pattern, were not depleted in the RAC1 inhibitortreated cells (Table S3). We thought that identification of NUC RAC1GEF(s) could help to refine RAC1 suppression, and hence, inhibition of NUC migration in the context of NB. As previous studies showed, three GEFs, T-lymphoma and metastasis gene 1 TIAM1, triple functional domain protein TRIO and TRIO homologue kalirin, are inhibited by NSC23766 (Gao et al, 2004; Zeinieh et al, 2015). These GEFs, which were already implicated in NB biology (Molenaar et al, 2012; Pugh et al, 2013), were highly expressed in primary NB and NB cell lines (Fig S5A and B). To date, only Tiam1 was reported to activate Rac1 in the context of migrating mouse CNS neurons (Kawauchi et al, 2003). In primary NB, KALRN showed stronger coexpression with DCX and SOX11, compared with TRIO and TIAM1 (Fig $\mathrm{S} 5 \mathrm{C}$ ), indicating $A D R N$-type-specific expression of KALRN, which was also reflected by RNA profiles in NB cell lines (Fig 5A). We checked the expression of the three GEFs by WB using RAC1-GEF domainrelevant $A B s$, which showed a $160-k D$ band, identified as deltakalirin-8 (Mains et al, 1999, in primary MNA NB as well as ADRN cell lines, and a $115-\mathrm{kD}$ band in several MYCN-nonamplified primary NBS (Figs 5B and S5D). An AB against kalirin PDZ-binding motif (STYV) detected a 100-kD delta-kalirin-7 in several primary MYCN-nonamplified NB. TIAM1 isoforms were found in ADRN cell lines as well as several primary NBs. An anti-TRIO AB detected several annotated isoforms in one primary MYCN-amplified NB and a 50-kD band in the cell lines. As immunostaining showed, kalirin isoforms, like RAC1, had perinuclear and nucleolar localisation, whereas TRIO and TIAM1 were found only in nucleoli and in cell boundaries, respectively, which supported the likelihood of kalirin involvement in RAC1 activation and MT regulation (Figs $5 \mathrm{C}$ and S6A-C). TIAM1, TRIO, and KALRN are potentially regulatable by SOX11 (Table S2); therefore, we checked their expression by WB, which revealed a reduction of kalirin and TIAM1 levels in SOX11-KD IMR-32 cells (Fig S6D). Kalirin-SP and kalirin-STYV signals had uneven distribution at migration fronts of immunostained NB-S-124 (Fig S6E) and IMR-32 spheroids (data not shown), which was also confirmed by WB of sparsely seeded cells, suggesting that kalirin isoforms were functionally diversified (Fig 5D). We down-regulated the kalirin RAC1-GEF (GEF1) pharmacologically with the compounds that do not interfere with TIAM1-ITX3 (kalirin-GEF1 inhibitor\#1, $10 \mu \mathrm{M}$ ) and NPPD (kalirin-GEF1 inhibitor\#2, $5 \mu \mathrm{M}$ ) (Blangy et al, 2006; Ferraro et al, 2007; Bouquier et al, 2009; Yan et al, 2015). Active RAC1 levels were lower in IMR-32 and SK-N-BE(2)C treated with either RAC1 inhibitor or each of kalirin-GEF1 inhibitors. KALRN RNAi in IMR-32 (Fig S7A and B) also reduced RAC1 activity, thus confirming kalirin involvement in RAC1 activation (Figs 5E and S7C). This effect was not observed in the reprogrammed after SOX11 RNAi cells (Johnson et al, 2000).

Based on co-expression with DCX mRNA and WB results, several ADRN type-specific KALRN transcripts were produced in primary NB, which was confirmed by ChIP-seq profiling for H3K36me3 in NB cell lines (Fig 5F). H3K4me3 peaks' presence at exon-B and RAC1GEF-unrelated Duet exon in all tested cell lines along with H3K27me3 loading at the KALRN in MES cell lines was indicative of bivalency, associated with the genes involved in neuronal specification (Liu et al, 2017). Kalirin is expressed in the murine heart, adrenal medulla and superior cervical ganglia (May et al, 2002). Kalrn mRNAs demonstrated no affinity with a particular population on the t-SNE-processed expression data from mouse sympathetic precursors (Furlan et al, 2017; Fig S7D). More specifically, kalirin isoforms -9 and -12 are expressed in mature sympathetic neurons (May et al, 2002), kalirin-9 protein is expressed in cardiac outflow tract (Wu et al, 2013), whereas kalirin-8 protein is found in rat and mouse neuroendocrine cells (Hansel et al, 2001; Ferraro et al, 2007). ADRN-type cells are likely to inherit KALRN expression from a sympathoadrenal precursor. In line with this, kalirin-9 and -12 expression was higher in stage 4S NB (4S versus 4: $P$-value $=4.4 \times$ $10^{-6}$ [kalirin-9]; $P$-value $=9.1 \times 10^{-3}$ [kalirin-12] $)($ Fig 5G). Given the low contribution of Duet $5^{\prime}$-exons into KALRN isoform repertoire in NB, this indicated that kalirin-9 was the most highly expressed KALRN isoform in stage 4S. 3'-UTR diversity was identified for kalirin-9 because a sub-isoform with a cryptic 3'-UTR exon carrying a stop codon was present in IMR-32 (Fig S7E). On the other hand, as WB in primary tumors showed, kalirin-8 expression was associated with MYCN amplification, but not with MYCN expression, indicating its sub-lineage specificity. RT-PCR for 3'-most exons of kalirin-9 and -12 showed positive results in untreated IMR-32 and SK-N-BE2C (Fig $5 \mathrm{H}$ ), whereas the full-length kalirin-9 and -12 proteins were barely detectable and a kalirin-GEF2-relevant AB (Fig S5D) did not detect kalirin-8, which implied that other mechanisms (e.g., cleavage by calpains [Miller et al, 2017]) were involved in generating kalirin-8 in NB. Consistently, KALRN gene profiles from primary NB did not support kalirin-8 3'-UTR, which, along with the absence of 5'-most exons of A_23_P307563-detectable Duet and negative RT-PCR results for Duet, indicated the prevalence of kalirin-12 and kalirin-7 in ADRN NB (Fig $5 \mathrm{H}$ and I). Given the repertoire of kalirin isoforms in sympathetic neurons (May et al, 2002), we checked KALRN expression in a retinoic acid (RA)-induced neuronal differentiation model, SK-N-BE(2)c, and observed induction of kalirin-9 and kalirin12 mRNAs and proteins as well as suppression of kalirin-8 after RA treatment. We also noticed TRIO transcripts and proteins' strong induction, whereas TIAM1 mRNA levels remained unchanged (Fig S7F, left and top right). In IMR-32 cells, which are not amenable to differentiation, we observed neither kalirin-8 down-regulation nor induction of kalirin-9, -12, and TRIO (Fig S7F, bottom right).

Taken together, these results suggest that kalirin is involved in RAC1 activation in ADRN-type NB, particularly in its most aggressive, MNA sub-type. 
A

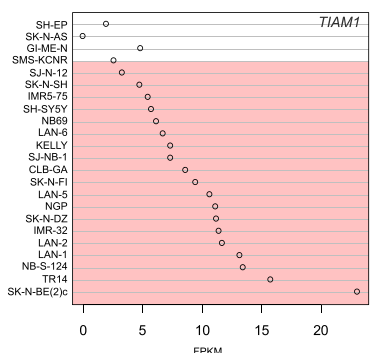

B

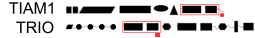
kalirin

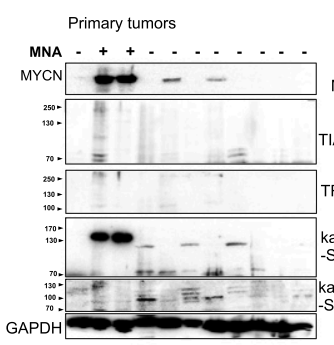

D

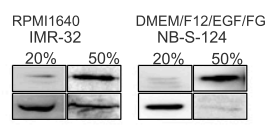

\section{Cell lines}
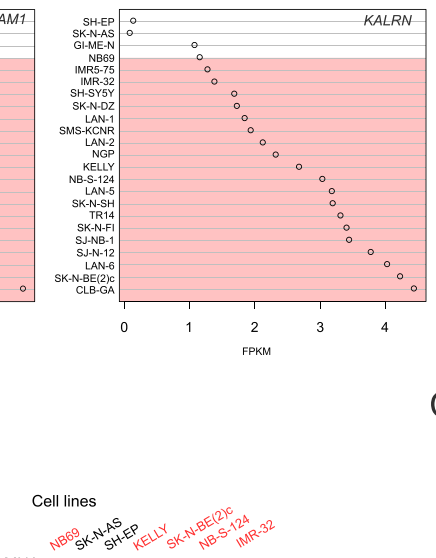

C
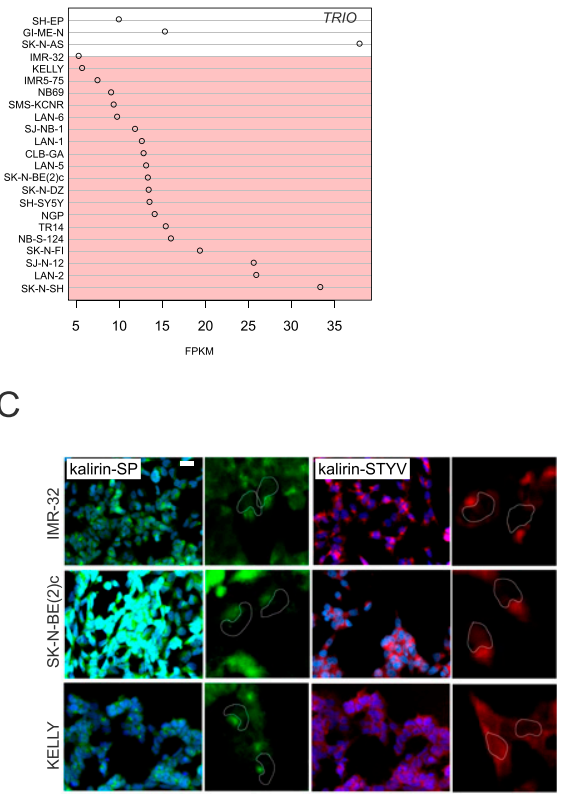

E

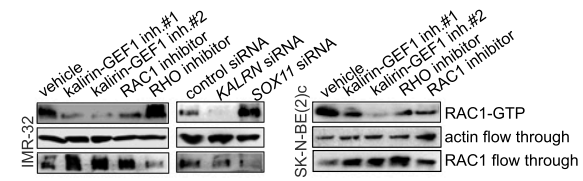

$\mathrm{F}$

TSS

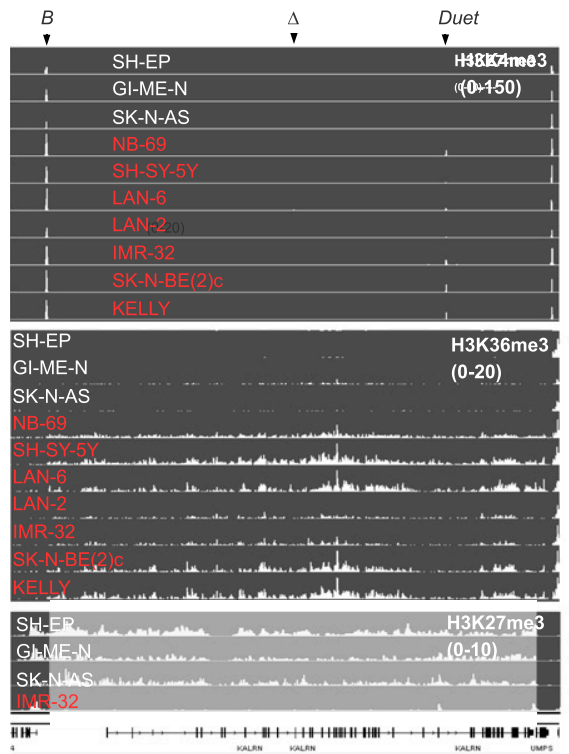

G

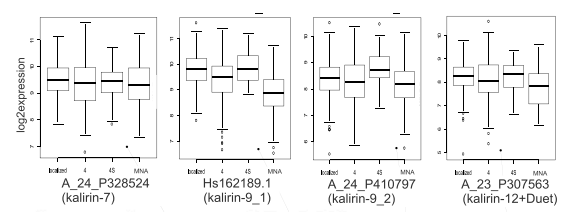

$\mathrm{H}$
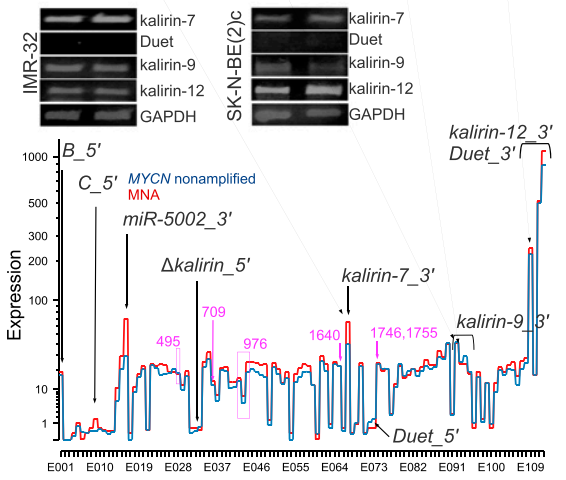

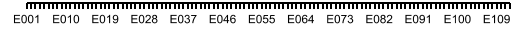

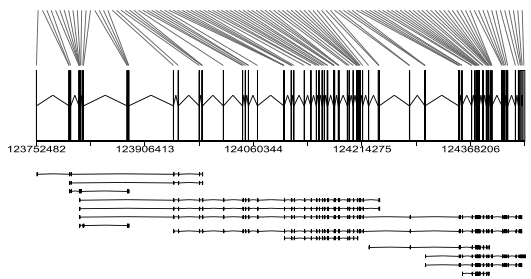

Figure 5. Kalirin is a NSC23766-sensitive RAC1-GEF in ADRN-type cells.

(A) TIAM1, KALRN, and TRIO mRNA expression in MES and ADRN (marked in red color) cell lines. (B) WB analysis of TIAM1, TRIO and kalirin in a panel of primary NBs, NB cell lines. Location of antigens and RAC1-GEF domains in TIAM1, TRIO, and kalirin proteins (top) is marked by red lines and boxes, respectively. MNA status in primary tumors and cell lines is indicated. The names of ADRN cell lines are marked in red color. (C) IMR-32, SK-N-BE(2)c, and KELLY were stained with anti-STYV and anti-kalirin-SP antibodies and visualized with Cy3- or Alexa 488-conjugated secondary antibodies. Nuclei are indicated by the dashed lines. (D) WB analysis of kalirin-SP and kalirin-STYV in MNA cell lines harvested at 20\% and 50\% confluency. (E) RAC1 activity in IMR-32 and SK-N-BE(2)c cell treated with kalirin-GEF1 inhibitor\#1 (10 $\mu$ M), 
Kalirin inhibition hinders NUC migration, evoking transcriptional signatures associated with low-risk characteristics in primary NB

Kalirin has not been identified as a regulator of NUC or MT function, as its functions are mainly attributed to the regulation of exocytosis and actin cytoskeleton in the post-migratory neurons. Moreover, kalirin is an extremely multifaceted molecule; therefore, we sought to carefully assess cell phenotype after kalirin suppression. Kalirin suppression did not affect cell viability (Fig S7G) and cell cycle distribution in NB cell lines (data not shown), which was in agreement with the pro-migratory role of RAC1. 2D exclusion assay revealed a decrease in migration after kalirin suppression in MNA ADRN cells and, to a lesser extent, in MYCN-nonamplified NB69, which was confirmed by cell tracking in IMR-32_NM and NB-S-124 (Figs $6 \mathrm{~A}$ and $\mathrm{B}$ and S8A and $\mathrm{B}$ ). As cell kymographs and |NC-CC| plotting demonstrated, kalirin-GEF1-suppressed IMR-32_NM displayed cell polarisation defects and NUC defects (Fig 6C and D and Video 7). Immunostaining showed that kalirin was not a centrosomal protein (Fig S6B), but rather colocalised with MTs and Golgi complex, which supported the idea of kalirin involvement in the regulation of the NUC function of MTs (Fig S8C). We noticed that, similar to $D C X$ - or SOX11-KD, the proportion of the nuclei with distally located centrosomes as well as a variability in the $\mathrm{N}-\mathrm{C}$ distance were lower in the cells after the suppression of kalirin or RAC1 inhibition (Figs 6E and S8D), indicating that the cells failed to translocate centrosomes, which was in line with the findings in neurons (Tanaka et al, 2004; Yang et al, 2012). Also, inhibition of either kalirin or RAC1 altered $\gamma$-tubulin distribution, suppressing extra-centrosomal $y$-tubulin signals (Fig S8E). The heterogeneity of nuclear shapes, observed in fixed IMR-32 cells, was decreased in the cells treated with the RAC1 inhibitor or after kalirin suppression, which was an additional indication of a reduction in the cell fraction primed for NUC (Fig 6F and G). We found less distal $\beta$ III-tubulin staining in the cells after kalirin suppression (Fig 6H). These alterations closely resembled the defects of nuclear elongation and LP formation, observed after the block of MT polymerization in neurons (Nishimura et al, 2017). Thereafter, we stained IMR-32 for F-actin by fluorescently labelled phalloidin, which revealed a reduction in perinuclear staining in kalirin-GEF1 inhibitor\#2-treated cells; therefore, actin regulation by kalirin could not be completely ruled out (Fig S8F). As a further test for kalirin involvement in NUC, we checked whether kalirin-GEF1 inhibition affected the expression of DCX, LIS1 and SOX11 and found down-regulation of DCX, but not SOX11, in the kalirin-GEF1-inhibited IMR-32 cells. These results suggested that kalirin suppression could reinforce migration inhibition via DCX downmodulation (Fig S8G). We checked whether DCX re-introduction (Tanaka et al, 2004) rescued migration in KALRN-KD cells. The substantial compensation of migration was observed in KALRN- and DCX-KD, but not in SOX11-KD IMR32_NM cells (Fig S8H). The most plausible explanation for this situation is the reprogramming taking place in SOX11-KD cells, which makes DCX irrelevant to cell migration. Kalirin-7 forced expression did not significantly affect motility nor induced differentiation in IMR-32, rescuing migration after application of $5 \mu \mathrm{M}$ kalirin-GEF1 inhibitor\#2 (Fig S9A; data not shown). We resolved migration defects by inspecting NNC/NCC angle distribution in IMR-32_NM after the suppression of RAC1 or kalirin (Fig 6I, left). Less NUC was observed in the RAC1- and kalirin-GEF1-inhibited cells, but NUC impact onto cell velocity was retained after RAC1- or kalirin-GEF1 inhibition (Fig 6I, right and Fig $6 J)$. This, along with the results of |NC-CC| plotting, implied that NUC suppression by RAC1 or kalirin-GEF1 inhibitors did not lead to migration mode reprogramming, which was consistent with the results of RNA-seq in RAC1- and kalirin-GEF1-inhibited IMR-32 (Table S3). Next, we resolved RAC1- and kalirin-GEF1-inhibited IMR-32 cells in the pseudo-3D assay and observed suppressed single cell motility after treatment with either of the inhibitors (Fig 6K). As NC-CC mapping showed (Fig 6I), RAC1- and kalirin-GEF1suppressed cells retained the impact of negative NC-CC within $0-40^{\circ}$ block, which was an indicator of cell contractions. This prompted us to test combination treatments with the ROCK inhibitor and RAC1 or kalirin-GEF1 inhibitors. The treatment with either of kalirin-GEF1 inhibitors or RAC1 inhibitor aided with ROCK inhibitor reduced cell viability in SK-N-BE(2)C (Fig S9B). This effect was not present in other cell lines. In the pseudo 3-D assay, we noticed spheroids' reduced dissociation after the addition of either of the kalirin-GEF1 inhibitors or RAC1 inhibitor to the ROCKsuppressed cells (Fig S9C) or addition of the ROCK inhibitor aided with either the RAC1 inhibitor or kalirin-GEF1 inhibitors (Fig S9D). Our data indicate that double treatments with ROCK- and kalirinGEF1 inhibitors could reinforce inhibition of migration. The data provided mechanistic evidence for the NUC function of kalirin in ADRN-type NB cells.

Analysis of RNA-seq-resolved profiles of kalirin-GEF1-inhibited IMR-32 showed that the up-regulated genes had an affinity with transcriptomes of stage 4S, MYCN-nonamplified tumors and stages 1/2 (Figs 7A and S10A). There was a significant transcriptomic overlap between kalirin-GEF1 inhibition and DCX RNAi or RAC1 inhibition in IMR-32, compared with the SOX11 RNAi (Fig S10B and C; data not shown). Similar to DCX RNAi, gene signatures RAC1 neighbourhood, mRNA transport and NMD, MYC(N) and TP53 targets, gene sets pertaining to mitochondrial function and cortical cytoarchitecture were depleted in kalirin-GEF1-inhibited cells (Fig 7B and Table S3). The depletion of TP53 and MYC(N) targets was a trait present under several NUC inhibitory conditions, including DCX-KD, LIS1-KD, SOX11-KD, and kalirin-GEF1-inhibited IMR-32 (Fig S10D); and TP53 RNAi induced migration defects in IMR-32_NM (Fig S10E), although the TP53-KD cells remained adherent (Video 8). The up-regulation of pseudogenes and TCF21-dependent genes was

kalirin-GEF1 inhibitor\#2 ( $5 \mu \mathrm{M})$, RHOA inhibitor $(3 \mu \mathrm{M})$, RAC1 inhibitor $(10 \mu \mathrm{M})$, or after SOX11 and KALRN RNAi. The cell lysates were incubated with RBD-Rhotekin or PAKPBD beads and the bound activated RHOA and RAC1 was analysed by Western blotting. Flow through fraction was analysed for RHOA and RAC1 expression as loading control. (F) H3K4me3, H3K36me3, and H3K27me3 ChIP-seq showing binding events at KALRN promoter and gene body in NB cell lines. ADRN cell lines are marked in red color. Arrows indicate transcription start sites. (G) Expression of kalirin isoforms in primary NBs. (H) RT-PCR for $3^{\prime}$-most exons of kalirin-7, kalirin-12, Duet and kalirin-9 in IMR-32 and SK-N-BE(2)c. (I) KALRN gene profile obtained from RNA-seq data analysis of 27 primary NBs. 5' -most exons, 3'-most exons of the isoforms are indicated, exons encoding known and high score calpain cleavage sites (predicted for the kalirin-12 [uniprot: 060229-1]) are marked in purple color. 
A

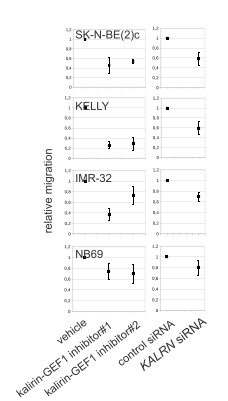

B

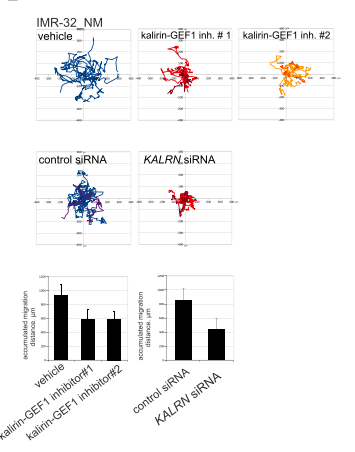

C

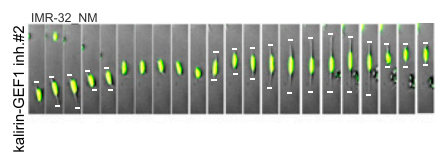

D

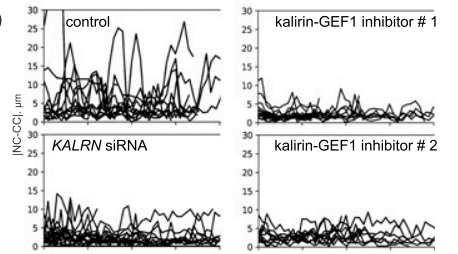

$50 \quad 100 \quad 150 \quad 200 \mathrm{~m}$
E

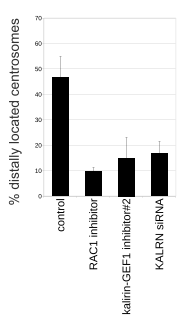

$\mathrm{H}$
$\mathrm{F}$

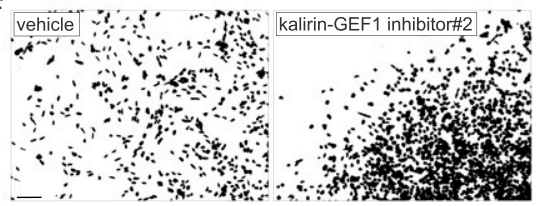

G

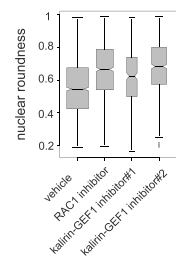

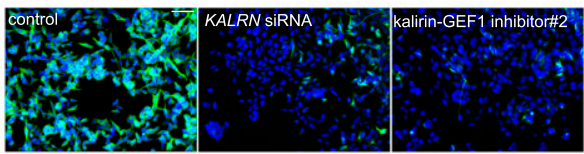

।

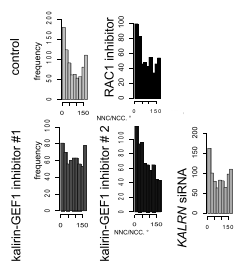

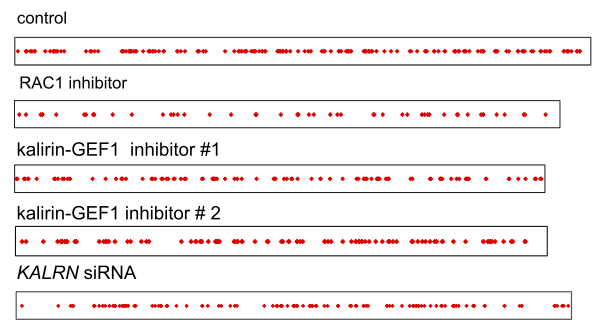

$\mathrm{J}$

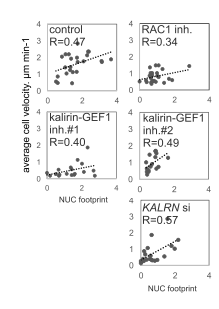

Figure 6. Kalirin inhibition hinders migration in MNA cells and perturbs cell polarisation and MT structure.

(A) Relative migration in 2D exclusion assay after treatment with vehicle, kalirin-GEF1 inhibitor\#1 (10 $\mu \mathrm{M})$ and kalirin-GEF1 inhibitor $\# 2$ (5 $\mu \mathrm{M})$ or after KALRN RNAi. Relative cell migration is quantified via normalization of cell density to vehicle- or siRNAtreated control. Graphs represent mean relative difference in migration + SD. (B) Random walk plots and accumulated migration distances in control IMR32 NM cell after treatment with kalirin-GEF1 inhibitor\#1 or kalirin-GEF1 inhibitor\#2, and after $48 \mathrm{~h}$ of KALRN RNAi (13 and 10 h, 15-min intervals). Mean values + SD are presented. (C) Time-lapse images of IMR-32_NM after kalirin-GEF1 inhibitor\#2 treatment. Nuclei and leading processes are indicated. Scale bar $20 \mu \mathrm{m}$. (D) $|\mathrm{NC}-\mathrm{CC}|$ plots in control IMR-32_NM and after treatment with kalirin-GEF1 inhibitor\#2, kalirin-GEF1 inhibitor\#1 or KALRN siRNA. (E) The percentage of centrosomes located distally in control, kalirin, or RAC1-suppressed IMR-32 cells. Mean values + SD are presented. (F) DAPI staining showing changes in the nucleus shape in IMR-32 after kalirin-GEF1 inhibition. (G) Box plots demonstrating nuclear roundness in IMR-32 cells treated with RAC1- or kalirin-GEF1 inhibitor. Data represent three independent experiments $(819,1,008$, 375 , and 772 cells). (H) $\beta 1 I I-t u b u l i n$ staining in control IMR-32 cells and after treatment with kalirin-GEF1 inhibitor\#2 or KALRN RNAi. The representative fields were photographed. Scale bar $100 \mu \mathrm{m}$. (I) NNC/NCC angle frequency distribution (left) and NUC and noise-corrected NC-CC distances in $0-40^{\circ}$ and $140-180^{\circ}$ signatures in concatenated tracks from control ( 25 cells and 866 cells), RAC1-inhibited (30 cells, 563 timepoints), kalirin-GEF1-inhibited (25 cells and 606 timepoints) and KALRN siRNA treated (30 cells and 860 timepoints) IMR-32_NM (right). (J) Correlation plots between cell velocity and NUC footprint in control IMR-32_NM and after treatment with RAC1 inhibitor, kalirin-GEF1 inhibitor\#1, kalirin-GEF1 inhibitor\#2, or KALRN siRNA. (K) Phase contrast images, random walk plots, and accumulated migration distances of randomly migrating cells treated with vehicle, RAC1 inhibitor (10 $\mu \mathrm{M})$, kalirin-GEF1 inhibitor\#1 $(10 \mu \mathrm{M})$ or kalirin-GEF1 inhibitor\#2 $(5 \mu \mathrm{M})$ for $48 \mathrm{~h}$ in pseudo-3-D (21 h, 90-min intervals). Mean values + SD are presented.

K

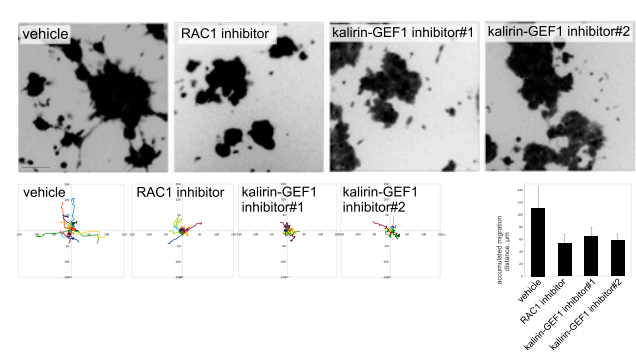

also a trait that RAC1-inhibited and kalirin-GEF1-inhibited IMR-32 shared with the DCX-KD cells (Figs 7B and S10F, left). TCF21 was highly expressed in stage $4 S$ (stage $4 S$ versus stage 4 , P-value < 0.001 ; stage $4 \mathrm{~S}$ versus MNA, $P$-value $<0.001$; one-way ANOVA test; Fig
S10F, right). Yet, we found neither a difference in TCF21 expression in the profiles of NUC-suppressed cells nor a possible proxy TF downstream of TCF21, which suggested other regulatory mechanisms behind the TCF21 signature in NB. The transcriptomic overlap 
A

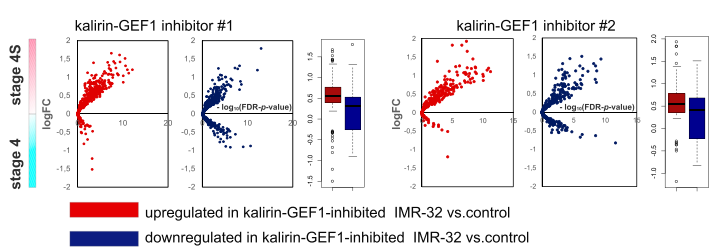

B

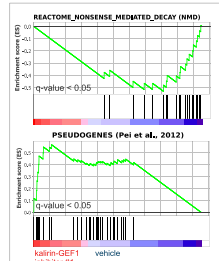

C
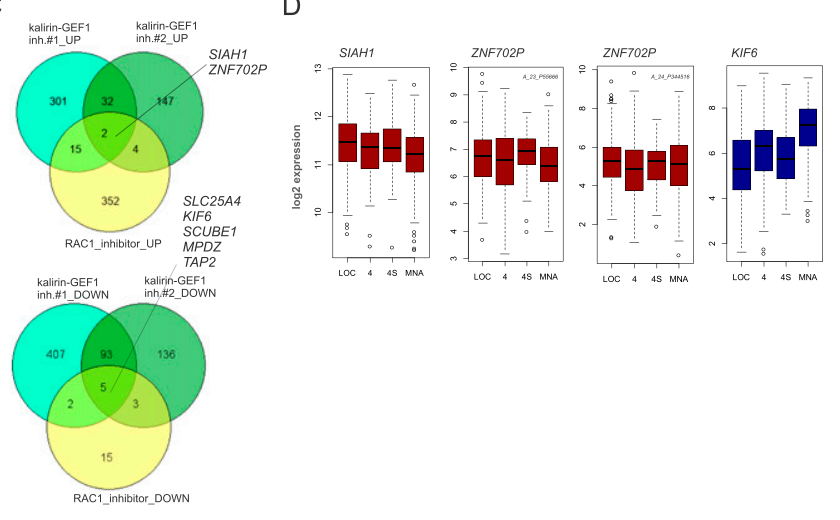

E

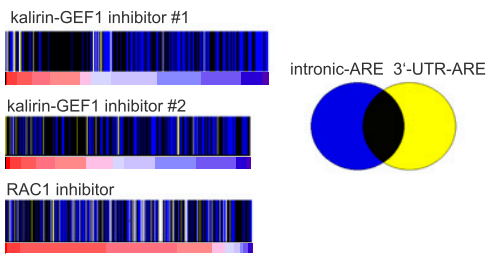

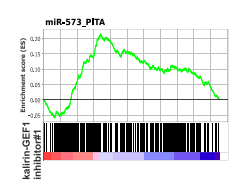

miR-53.-PraA |||||||||||||||||||||||||| $\mid$

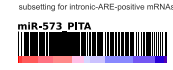

G

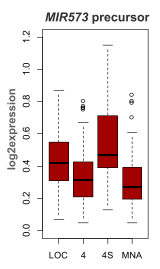

$\mathrm{H}$
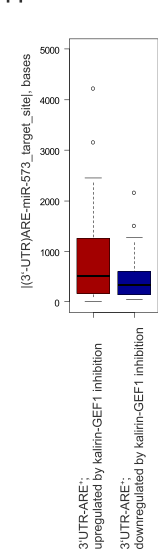

I

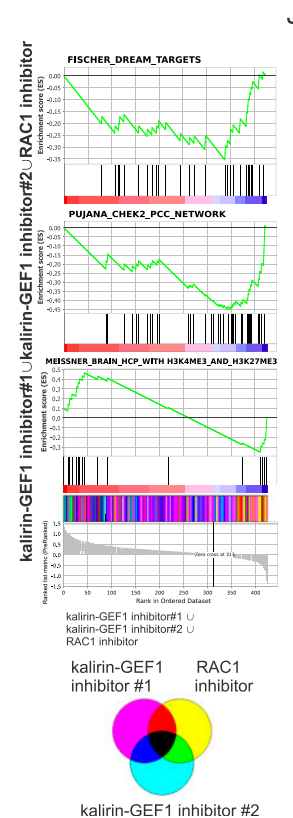

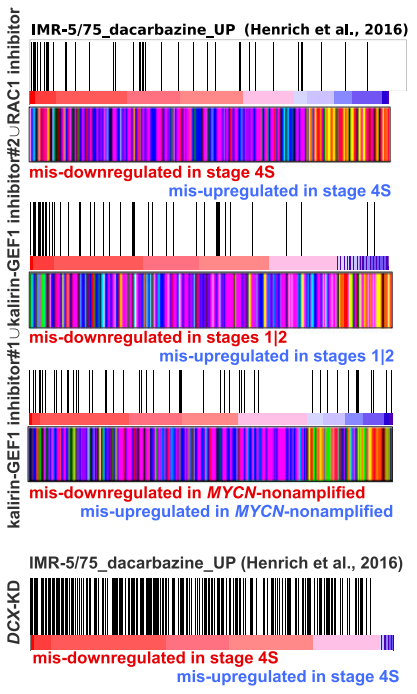

Figure 7. Inhibition of kalirin-GEF1 engages pathways of post-transcriptional gene regulation.

(A) Volcano plots showing expression of DEGs in kalirin-GEF1-inhibited cells versus control in stage $4 \mathrm{~S}$ versus 4 tumors (gse49710). (B) Gene set enrichment analysis plots showing genes sets with similar pattern of regulation in kalirin-GEF1-inhibited and DCX-KD IMR-32. (C) Venn diagram showing the number of genes in transcriptomic overlap between DEGs in RAC1 inhibitor-, kalirin-GEF1 inhibitor\#1- and kalirin-GEF1 inhibitor\#2-treated IMR-32 versus control. (D) Box plots demonstrating ZNF702P, SIAH1, and KIF6 expression in primary NB tumors. (E) Color-coded scheme showing gene overlaps between 3'-UTR- and intronic-AU-rich element (ARE)-containing genes (Bakheet et al, 2018) in the ranked lists of DEGs in RAC1- and kalirin-GEF1-inhibited IMR-32 versus control IMR32. (F) Enrichment plots for miR-573 targets ("miR573_PITA") based on PITA algorithm (Kertesz et al, 2007) in IMR-32-treated with kalirin-GEF1 inhibitor\#1 versus control (top). Diagrams demonstrating miR-573 targets in the ranked gene subsets of 3'-UTR-ARE and intronic ARE containing genes from IMR-32-treated with kalirin-GEF1 inhibitor\#1 versus control (bottom). (G) Box plot demonstrating MIR573 expression in primary NB tumors (gse62564) (left) and volcano plot showing expression of predicted miR-573 targets (right) in stage 4 S versus 4 tumors. (H) Box plot showing distances between AREs and miR573-binding sites in $3^{\prime}$-UTRS of DEGs in kalirin-GEF1-inhibited cells. P-value: 0.005 (twosample Kolmogorov-Smirnov test). (I) Gene set enrichment analysis plots for the indicated gene sets (top) in the combined list of genes misregulated (based on their mis-expression in stage $4 S$ versus stage 4 tumors [ $P$-values by two-way $t$ test $\leq 0.05$; no logFC cutoff]) in RAC1- and

kalirin-GEF1-inhibited IMR-32. Color-coded scheme showing gene overlaps (bottom) between misexpressed genes extracted from profiles of kalirin-GEF1- and RAC1-inhibited cells and ranked according to their expression in stage $4 \mathrm{~S}$ versus stage 4. (J) Diagrams showing positions of the genes up-regulated by dacarbazine in ADRN-type cell lines (Henrich et al, 2016) in the combined lists of genes mis-regulated in RAC1- and kalirin-GEF1-inhibited (top) and DCX-KD IMR-32 (bottom). within the group "RAC1 inhibitor and kalirin-GEF1 inhibitors" ( $P$ value cutoff, 0.12; Kruskal-Wallis test) included up-regulation of ZNF702P, ETV1 (lowest $P$-value < 0.02), and SIAH1 (lowest $P$-value < 0.03), as well as down-regulation of KIF6, SCUBE1, EHMT1, and MPDZ (lowest $P$-value $<0.03$ ) (Fig $7 C$ and Table S3). The expression of ZNF702P and SIAH1 was associated with certain low-risk characteristics in NB (stage 1 versus stage 4, P-value < 0.05; MYCN-nonamplified versus MNA, $P$-value $<0.05$; one-way ANOVA test), 
whereas KIF6 was highly expressed in stage 4 and MNA NB (stage 4 versus LOC, $P$-value < 0.001; MNA versus MYCN-nonamplified tumors, $P$-value $<0.001$, one-way ANOVA test, Fig 7D). The genes correlated with ZNF702P, SIAH1, and KIF6 extracted from the gse 49710 dataset showed overlaps with the profiles of kalirin-GEF1- and RAC1-inhibited cells (Fig S11A). As ZNF702P was down-regulated in the SOX11-KD cells (Table S2), we checked the lineage affinity of ZNF702P mRNA, which revealed ADRN type-specific ZNF702P expression (Fig S11B). Pseudogene function as miRNA decoys was documented before (Poliseno et al, 2010); therefore, we checked available miRNA-pseudogene interaction data ( $\mathrm{Li}$ et al, 2014), which revealed the binding of several miRNA species to ZNF702P mRNA (Table S4).

Given the regulation of RNA-binding protein-encoding mRNAs in kalirin-GEF1-inhibited cells, cross-checking of our datasets for genes containing AU-rich elements (AREs) (Bakheet et al, 2018) was reasonable, which revealed the prevalence of ARE-containing mRNAs in the up-regulated genes of kalirin-GEF1-inhibited cells (Figs 7E and S11C and Table S4). The enrichment involved mRNAs with 3'-UTR- and intronic AREs. Sub-setting for 3'-UTR-ARE- and intronic ARE-containing genes revealed that they were enriched for the targets of miR-181-5p, miR-153-5p, miR-335-3p, miR-493-5p, miR-12136, and miR-548-5p/3609-3p and the motif "AACTTT_UNKNOWN" (Table S4). Given the criteria for AACTTT selection (8 kb surrounding a transcription start site; Xie et al, 2005), we reasoned that "AACTTT" motif represented an intronic binding site for a miRNA. miRBase inspection showed that nucleotide string "AACUUU" is potentially targeted by miR-148a-5p, miR-548at-5p, miR-561-5p, and the juxtaposed to miR-12136 sequence "326_104" at 1p36.33, cloned previously from an MNA NB tumor (Afanasyeva et al, 2008). The miRNA precursors, MIR181A2 and MIR3609, were downregulated in kalirin-GEF1-inhibited cells (Table S3), which could explain the up-regulation of miR-181 and miR-3609 targets. These two miRNA genes, together with MIR573 and MIR873, were present in profile overlaps after at least two of the NUC inhibitory treatments used in this study (DCX RNAi, LIS1 RNAi, SOX11 RNAi, and RAC1/ kalirin-GEF1 inhibition), suggesting essential functions of these miRNAs in NUC regulation. Yet, ARE-positive genes potentially targeted by miR-573 were up-regulated in kalirin-GEF1-inhibited cells (Figs 7F and S11D). A similar effect was visible in DCX-KD, after subsetting the profile for ARE-positive genes (Fig S11D). The expression of MIR573 precursor was higher in stage $4 S$ and LOC tumors (Fig 7G, left; P-values < 0.001; one-way ANOVA test). Also, the expression of predicted miR-573 targets showed affinity to stage $4 \mathrm{~S}$ and stages 1/2. (Fig 7G, right, data not shown). Genes correlated positively with MIR573 expression in primary NB were enriched for miR-573 targets (Fig S11E). miR-873 targets showed a similar pattern of expression in kalirin-GEF1-inhibitor\#1-treated IMR-32, but not in the DCX- and LIS1-KD cells (Fig S11F). Potential miR-573 binding sites and confirmed experimentally miR-873 binding sites (Li et al, 2014) were localised further from 3'-UTR ARES in the ARE-containing up-regulated genes compared with the ARE-containing downregulated genes in kalirin-GEF1-inhibited cells (Figs $7 \mathrm{H}$ and S11G). Therefore, the up-regulation might require a function in cis of ARE-binding complexes and miRNA-induced silencing complexes (miRISCS). The enrichment for ARE-positive miRNA targets of miR181-5p, miR-153-5p, miR-335-3p, miR-493-5p, miR-12136, and miR- 548-5p/3609-3p was also apparent in the transcriptomes of stage $4 S$ and stages $1 \mid 2$, compared with stage 4 primary tumors (Table S4). Similar to DCX-KD, kalirin-GEF1 inhibitor ${ }^{\mathrm{UP}}$ and NB_DTC UP gene sets formed an overlap (Fig S11H, left), which was an indication that kalirin-GEF1 inhibition took place in NB in vivo. Also, affinity of miR573 targets, 3'-UTR- and intronic-ARE-positive mRNAs with transcriptomes of DTCS was observed (Fig S11H, right).

Next, we checked whether and RAC1- and kalirin-GEF1 inhibition affects cell death induced by doxorubicin, paclitaxel, vincristine, and exherin in IMR-32 and SK-N-BE(2)c and observed only minor interaction with the MT drugs, vincristine and paclitaxel (Fig S111, data not shown). Our data indicated that mis-expression mainly affected down-regulation in RAC1- and kalirin-GEF1-inhibited cells; therefore, possible vulnerabilities were to be found in the mechanisms of down-regulation. We combined mis-expressed genes extracted from the transcriptomic profiles of RAC1- and kalirinGEF1-inhibited cells and subjected derived lists to GSEA, which revealed the presence of CHEK2 neighbourhood and DREAM targets in a small subset of mis-up-regulated genes (Fig 71 and Table S4). The subset of mis-down-regulated genes was enriched for bivalently marked genes (Fig $7 \mathrm{l}$ ). This suggested that the activity of the polycomb repressive complex was responsible for the gene downregulation in the NUC-suppressed cells. Several prospective epigenetic modifiers, including EZH2 inhibitors, were already tested in NB (Henrich et al, 2016; Chen et al, 2018). Yet, the genes up-regulated after treatment of ADRN-type cell line, IMR-5/75, with an EZH2 inhibitor (Henrich et al, 2016) showed little overlap with the profiles of kalirin-GEF1- and RAC1-inhibited IMR-32 (data not shown). On the other hand, the genes up-regulated after the treatment with the DNA-methyltransferase inhibitor (DNMT) dacarbazine showed an overlap with mis-down-regulated genes in kalirin-GEF1- and RAC1inhibited IMR-32 as well as DCX-KD cells (Fig 7J), implying that dynamic DNA methylation might take place in the NUC-suppressed cells. Taken together, these data show that pharmacological inhibition of kalirin-GEF1 evokes transcriptomic traits of low-risk NB.

Our data provide evidence that gene up-regulation driven by kalirin-GEF1 inhibition operates via miRNA-dependent posttranscriptional mechanisms. Most importantly, our analyses suggest that suppressors of epigenetically driven gene down-regulation might interact with kalirin-GEF1 inhibitors synergistically, which should be checked in future experiments.

\section{Discussion}

Intact NUC is necessary for neuronal positioning, but its relevance to cancer, particularly to cancer cell migration, has not been elucidated. In this study, we present evidence that NUC is active in ADRN-type NB. Previous studies revealed the RHOA-ROCK pathway's functionality in NB migration (Matas-Rico et al, 2016). Our study shows that intact migration in ADRN-type NB requires ROCK and RAC1. The interference with the function of RAC1 and the RAC1GEF, kalirin, leads to severe defects in NUC migration, evoking several transcriptional features of low-risk NB.

Migration in NB is thought to recapitulate certain traits of neural crest-derived cells of origin (Ratner et al, 2016; Delloye-Bourgeois \& Castellani, 2018). However, it is unlikely that NUC is active during the 
development of sympathetic ganglia. We could not find any information about the involvement of postganglionic sympathetic structures in Lis1 KO and Dcx KO mice. Also, only a few cases have been reported when individuals with lissencephaly had heterotopias and/or hypoganglionosis in the PNS (Mittal et al, 2014). There is one indication that Lis1 is involved in the tangential migration of certain sympathetic preganglionic neurons (Moore et al, 2012). Evolutionary younger than other neural crest derivatives postganglionic sympathetic elements emerge in gnathostoma through phox2, ascl1 and hand coalescence into an expression module (Häming et al, 2011). Therefore, the correspondence between NUC migration in NB and CNS might manifest during the development of the neuronal subtypes expressing NB-like TF code, that is, hindbrain (nor)adrenergic neuronal formations (Zeisel et al, 2018). Particularly, facial branchiomotor neurons demonstrate $\mathrm{N}-\mathrm{C}$ inversions when migrating tangentially (Distel et al, 2010). Also, motor neurons migrate tangentially in a reelin-negative region (Rossel et al, 2005), which is an interesting notion when put in the context of RELN negativeness of advanced NB (Becker et al, 2012). Probably, migrating ADRN NB resembles motor neurons, but "gets stuck" at the stage of tangential migration-like centrosomal repolarisation. Remarkably, murine orthologue of up-regulated in kalirin-GEF1-inhibited cells ETV1 is expressed in the nuclei of mouse cranial nerves (Zeisel et al, 2018). More precisely, Etv1 expression appears in facial motor neurons during the final posttangential stage of their migration, the sub-nuclear segregation, and is indispensable for finalising neuronal differentiation (Zhu \& Guthrie, 2013; Tenney et al, 2019). Kalirin-GEF1 inhibition upregulates low-risk specific transcriptomic traits in ADRN NB, which can be interpreted as a sign of a differentiation-like process. Yet, it is the kalirin paralog, Trio, that is involved in facial motor sub-nuclear segregation in mice (Backer et al, 2007). On the other hand, in xenopus, kalrn expression is present in the cranial nerves, whereas trio is expressed in migrating neural crest cells (Kratzer et al, 2019). In fact, kalirin and trio originated through the duplication of a proto-trio/kalirin gene in the ancestral invertebrate, but became first stabilised and functionally diversified in cyclostomata (Kratzer et al, 2019). Probably, kalirin-dependent NUC migration in ADRN NB recapitulates the relict hindbrain migration. It would thus be interesting to assess neuronal migration in the hindbrain of kalrn morphants.

Given the parallelism between neuronal and NB migration, it is reasonable to check if there have been any studies reporting the co-occurrence of NB and neuronal overmigration in the CNS. Indeed, a possible manifestation of neuronal overmigration, cortical polymicrogyria (Squier \& Jansen, 2014), is found in Weaver syndrome, which is caused by mutations in the EZH2 gene (TattonBrown et al, 2013), and in a neuroactive drug embryopathy, fetal hydantoin syndrome (Al-Shammri et al, 1992). Importantly, these disorders rarely involve only the forebrain, but also manifest in hindbrain malformations. Both of these conditions are associated with a higher risk of NB. Interestingly, two NB cases reported in children with Weaver syndrome were stage $4 S$ tumors. Also, some NB tumors that were observed in children with fetal hydantoin syndrome were diagnosed perinatally (Al-Shammri et al, 1992), which may be indicative of low-risk stage tumors. Remarkably, polymicrogyria loci include 1p36 (Dobyns et al, 2008) which is frequently deleted in NB tumors (White et al, 2001). A small percentage of children with constitutive 1p36 monosomy developed NB tumors which regressed spontaneously (Biegel et al, 1993; Isidor et al, 2008). It is tempting to speculate that the stage 4S NB also stems from being ectopically activated and supported by fetally expressed chemokines NUC migration rather than neural crest-like forms of migration. Furthermore, NUC deactivation via cell-nonautonomous events (e.g., via fetal to neonatal transcriptome switches that affects NB homing) may trigger programmed cell death in stage $4 \mathrm{~S}$ tumors. Therefore, the functional assessment of polymicrogyria candidate genes, for example, 1 p36 candidates, $\alpha$-enolase encoding ENO1, and arginine-glutamic acid dipeptide repeats protein-encoding RERE (Jordan et al, 2015; El Waly et al, 2020), in the context of NB can be very informative.

Similar to postganglionic sympathetic structures, the hindbrain is rarely involved in classic forms of lissencephaly (Jissendi-Tchofo et al, 2009), which is, in part, caused by the functional redundancy of NUC regulators. In line with that, double Dcx, Dclk1 KO mice have severe cerebellar and brainstem defects and resemble Cdk5 KO (Ohshima et al, 1996; Deuel et al, 2006). Because of the function of NUC genes in differentiation and migration, migration in ADRN NB cells likely relies on a minimal set of NUC genes. Particularly, LIS1 that normally controls spindle assembly in NE is not involved in proliferation maintenance in ADRN NB, which supports the idea of NUC gene module. NUC activity in G1, migration inhibition in TP53KD cells and down-regulation of TP53 targets in NUC inhibited cells suggest that NUC migration is intertwined with the control of cell cycle transition in NB. TP53 regulates genes encoding NUCcontrolling cyclin inhibitors (Kawauchi \& Nabeshima, 2019) such as CDKN1C (p57kip), and genes involved in synapse maintenance (Merlo et al, 2014). Given the low frequency of TP53 mutations in NB, it is plausible that a part of p53 activity is rerouted to the NUC program. On the other hand, TP53mut ADRN NB cell lines are also affected by NUC. How TP53mut cells bypass TP53 control of NUC also remains to be answered. In addition, DCX and LIS1 functions are not confined to NUC because of their involvement in MT transport and regeneration in PNS (Nawabi et al, 2015; Hines et al, 2018). The defects in LP and lack of significant alterations in $\mathrm{N}-\mathrm{C}$ distance, which we observed in DCX-KD cells, conform with this idea. Also, ADRN NB terminals are reminiscent of pheochromocytoma' varicones (Mingorance-LeMeur \& O'Connor, 2009), which are akin to exocytotically active postsynapses. So far, nothing is known about their propensity to transduce pro-survival and cell death signals to the nucleus. We can speculate that MT dysfunction in the terminals of NUC-inhibited cells leads to the collapse of pro-survival retrograde signals, which manifests in the down-regulation of metabolic signatures. In line with that, the shut-down of mitochondrial function has been noticed previously upon KD of Dcx paralog, Dclk1, in mouse NB cells (Verissimo et al, 2010). The N-C inversion mode of NUC observed in NB cannot be explained by dynein-dependent forces (Sakakibara et al, 2013), implying the involvement of actinbased forces. Nevertheless, in ADRN NB, MT function lies upstream of actomyosin forces. MT-binding proteins such as DCX can serve as bridges between MTs and actin in neurons (Nawabi et al, 2015); MT destabilisation in ADRN NB cells might disrupt these links, crushing the entire migration machinery. The $\mathrm{N}$ - $\mathrm{C}$-inversion mode requires the concerted action of process maturation and dynamic N-C 
attachment. Most likely, kalirin-GEF1 inhibition locks centrosomes in an attached state.

Whereas neurons are not able to activate safeguard migration modes, cancer cells frequently undergo transitions from one migration type to another. The RNAi of a regulator of NUC in the CNS, SOX11, triggers NUC-to-MES transition in ADRN-type cells. Yet, the reprogramming is not limited to the migration mode but also affects cell identity, manifesting in ADRN-to-MES transition. The lack of direct binding of SOX11 to DCX promoter makes reasonable a search for neuron-specific, SOX11-responsive TFs that regulate the DCX promoter (Piens et al, 2010). We cannot conclude whether the regulation of DCX "by proxy" is inherited from a neural crest precursor or appear during ADRN NB oncogenesis. Particularly, in ADRN NB, apart from DCX, SOX11 might be ousted from other "legal" locations by MYCN (Zeid et al, 2018). This may explain why previously identified SOX11 targets do not show statistically significant depletion in SOX11-KD cells. The effects of SOX11-KD can be partially explained by the down-regulation of SOX11dependent ELAVL2, which positively regulates the stability of mRNAs in neurons (Scheckel et al, 2016). Also, ADRN-to-MES transition after SOX11 RNAi can be caused by the asymmetric distribution of mRNAs encoding ADRN determinants, rather than by withheld transcriptional control of these determinants. Recently, the identity-affecting asymmetric distribution of lysosomes and nuclear promyelocytic leukemia bodies triggered by nuclear migrations was observed in keratinocytes (Lång et al, 2018). A similar process might take place in SOX11-KD cells, as nuclei show a tendency towards apical localisation in SOX11-KD cells. SOX11 RNAi may thus eliminate "carriers" of ADRN determinants, whereas not affecting the mesenchymalised counterparts, which would explain the compensated shedding of pyknotic cells that was visible in SOX11-KD IMR-32. The best way to test this idea is through live imaging with to-be-designed ADRN and MES sensors. Also, if this idea is true, SOX11-suppressed cells should be an amalgam of transitory states; it is worth it, therefore, to resolve the SOX11 RNAi population using single-cell sequencing. Importantly, SOX11 down-modulation and EMT induction do take place after chemotherapy in NB. Hence, asymmetric divisions, if their association with the generation of MES cells is proven in vivo, may be an unwanted consequence of certain chemotherapy strategies in NB.

Remarkably, none of MES "heavy artillery" SE-associated TFs, such as PRRX1 (van Groningen et al, 2017), are induced after SOX11 RNAi. Prrx1-expressing mouse mesenchyme separates from a bipotent autonomic-mesenchymal precursor (Soldatov et al, 2019). None of ADRN-to-MES transitions identified so far, except for PRRX1 enforced expression, evoked PRRX1 expression, and events like SOX11 KD may generate an intermediate cellular compartment that can "descend" to a PRRX1 $1^{+}$MES precursor. In mice, Sox 11 mRNA is present in the bridge cell population that connects Schwann cell precursors with chromaffin cells (Furlan et al, 2017) and is indispensable for the proliferation of tyrosine hydroxylase-expressing precursors in developing sympathetic ganglia (Potzner et al, 2010). It would be interesting to test whether ectopically asymmetric cell divisions are related to Coffin-Siris syndrome's association with schwannomatosis (Schrier et al, 2012). Following this idea, an efficient NUC inhibitor should suppress migration without hampering the symmetricity of divisions, which adds complexity to the concept of separate targeting of proliferation and migration (Brabletz, 2012). Pending future mouse experiments, it is important to mention that NB DTC (Rifatbegovic et al, 2018) transcriptomes are recapitulated by DCX RNAi and kalirinGEF1 inhibition. It is tempting to speculate that the fingerprints in DTC profiles formed by DCX-KD and kalirin-GEF1 inhibitors reflect DTC heterogeneity and originate from regression events.

Importantly, ADRN NB cells treated with different kalirin-GEF1 inhibitors develop several overlapping gene expression patterns, e.g., down-regulation of NMD gene signature. NB is renowned for its low mutational load (Pugh et al, 2013); therefore, the reason for NMD maintenance in NB should lie outside the concept of NMD-driven degradation of mutated tumor suppressor-encoding RNAs (Popp \& Maquat, 2018). We believe NMD inhibition is linked to pseudogene RNA boosting in kalirin-GEF1-inhibited NB cells. It is plausible that transcribed pseudogenes function as miRNA decoys in NB cells. Yet, the expression of matching protein-coding counterparts is not affected by kalirin-GEF1 inhibition, suggesting the involvement of secondary miRNA targets. Particularly, this pertains to the top candidate, humanspecific ZNF702P at 19q13.4. As ENCORI database mining reveals, ZNF702P RNA binds NB metastasis-associated miR-181a-5p and miR23a-3p (Cheng et al, 2014; Gibert et al, 2014; Liu et al, 2018). Thus, ZNF702P can be responsible for the up-regulation of miR-181a targets in kalirin-GEF1-inhibited cells. A miR-181a precursor, MIR181A2, was down-regulated in kalirin-GEF1-inhibited cells, which cannot be explained by a direct target-induced miRNA degradation (Haas et al, 2016). Also, MIR181 pops-up in several transcriptomic profiles in this study, suggesting an essential role for miR-181a in ADRN NB migration. Importantly, these observations have parallels in neurons. NMD is an important mechanism of axon pathfinding and synapse maintenance (Long et al, 2010; Colak et al, 2013), and its defects have resulted in several neurodevelopmental illnesses (Jaffrey \& Wilkinson, 2018). Also, a recent study showed that pseudogenes' competition with coding genes for miRNAs has functional relevance in the CNS (Barbash et al, 2017). Yet, pseudogenes are mostly non-conserved, which also pertains to ZNF702P and other pseudogenes that are regulated by kalirin-GEF1 inhibition. ZNF702P possibly adopts a decoy role from a conserved counterpart. Also, ZNF702P is expressed not only in the hindbrain, but also in macrophages and lymphocytes, suggesting a broad range of its functions. Furthermore, the expression of the kalirin-9 isoform with a stop-codon carrying cryptic exon can be explained by the concerted action of two types of machinery: NMD inhibition and alternative splicing. The latter can, in turn, explain high kalirin-9 expression in stage $4 \mathrm{~S}$ tumors that may have consequences in overall RAC1 activity in NB in vivo (Deo et al, 2012).

Several genes that are down-regulated by kalirin-GEF1/RAC1 inhibition cannot be assigned to a particular gene signature. One such "orphan" gene, kinesin family member KIF6 at 6p21.2, is thought to influence cilia function (Konjikusic et al, 2018). Cilia support neuronal migration (Higginbotham et al, 2012) in the CNS via conducting SHH signals (Baudoin et al, 2012). In primary NB, KIF6 mRNA correlated genes contains few MT signatures, being enriched for the genes pertaining to ER-mitochondria-peroxisome nexus. Down-regulation of mitochondrial signatures repeatedly appears in NUC-inhibited cells. KIF6 down-regulation might eliminate a metabolic add-on that is indispensable for the migration. Another promising candidate, Kleefstra syndrome-associated euchromatic histone lysine methyltransferase 1 EHMT1 at 9q34.3, encoding a SOX11-interacting methyltransferase (Heim, 2014). Kleefstra syndrome, a neurodevelopmental disorder characterised by impaired 
memory, autistic features and intellectual disability (Benevento et al, 2016), shares several clinical traits with an SOX11 deficiency disease: Coffin-Siris syndrome. Intriguingly, abrogation of EHMT1 activity in neurons results not only in anticipated gene expression up-regulation but also in H3K9me3-mediated down-regulation of a gene subset, including clustered protocadherins (Iacono et al, 2018). It would be interesting to test whether loss of EHMT1 occupancy triggers an invasion of EZH-driven heterochromatinisation machinery in NB cells.

When compared with the mRNAs down-regulated in kalirinGEF1-inhibited cells, the up-regulated mRNAs do not appear to be organised into expression signatures, while showing strong expression affinity to NB subsets with low-risk characteristics. We reasoned that posttranscriptional mechanisms might be a clue to the up-regulation mechanism, which led to a rather serendipitous identification of 3'-UTR- and intronic ARE elements bearing genes up-regulation in kalirin-GEF1-inhibited cells. The mechanism behind this enrichment remains to be identified. We believe this upregulation is afflicted by miRNA-induced induction that takes place when AREs and MREs co-occur (Vasudevan \& Steitz, 2007). MIR573 at 4p15.2 and MIR873 at 9p21.1 are candidate "MRE-code" miRNAs that may act in an antagonistic way in NB depending on the status of miRISC complex. Importantly, the list of these "switcheroo" miRNAs does not include miR-16 that targets ARE motif directly (Jing et al, 2005). When mapped to the profiles of kalirin-GEF1-inhibited cells, up-regulated "ARE+; MRE-code+" mRNAs form dense "fingerprints" with moderately high median FC values. Similar fingerprints are also identifiable when profiles from kalirin-GEF1-inhibited cells are mapped onto expression profiles from NB DTC as well as stage 4 versus $4 S$ expression dichotomies. These findings provide strong evidence that kalirin-GEF1 inhibition occurs in NB in vivo. It is known that weak repression by miRNAs can nevertheless have a substantial effect on cell phenotype (Flynt \& Lai, 2008). Recently, data have been obtained supporting an FC threshold as low as 1.3 for functional miRNA targets (Yoon et al, 2019). This threshold can apply to the miRNA-induced mRNA up-regulation. Nevertheless, we could not find any perturbations in the expression of miRISCencoding mRNAs in kalirin-GEF1-inhibited cells, which suggests that other mechanisms (i.e., posttranslational modification) are involved in miRISC regulation. Indeed, the function of a component of miRISC, fragile $X$ mental retardation syndrome-related protein 1 , FXR1, is influenced by p21-activated kinase, PAK1 (Say et al, 2010), which, in turn, is potentially activable by kalirin-RAC1. These findings are also a plausible explanation as to why kalirin proteins are consistently found in the nuclei of NB cells. Importantly, gene up-regulation and translation activation by miRNAs are normally observed upon G1/G0 growth arrest and associated with quiescence and differentiation (Vasudevan \& Steitz, 2007); therefore, the enrichment for ARE-MRE containing mRNAs is likely a remnant of a differentiation program. Whether or not this phenomenon occurs specifically in regressing versus advanced NB tumors should be clarified in further research.

The administration of anti-migration drugs is devised to be continuous; therefore, the requirements for low toxicity of migration blockers are very stringent (Gandalovičová et al, 2017). As our experiments demonstrate, kalirin-GEF1 inhibitors fit this criterion in vitro. Also, studies with KO mice demonstrate that Kalrn is dispensable for CNS and PNS development (Mandela et al, 2012), which provides additional support for kalirin as a suitable target for migration blockers in NB. Indeed, in the CNS, errors in migration resulting in ectopic neurons are not uncommon as demonstrated by mice $\mathrm{KO}$ for $\mathrm{BCl}-2$-associated $\mathrm{X}$ protein-encoding, Bax (Jung et al, 2008). However, in sympathetic ganglia of Bax KO mice, increased neuronal survival in situ rather than gross ectopias are observed (Deckwerth et al, 1996). Kalirin suppression with an antisense RNA does not affect the survival of mature sympathetic neurons (May et al, 2002). Yet, we still cannot exclude the possibility that kalirinGEF1 inhibition is involved in programmed cell death in stage 4S NB cells, being insufficient to purge those NB cells that harbour secondary alterations (e.g., MYCN amplification). This complete uncoupling from proliferation together with the observation that mis-expression induced by kalirin-GEF1 inhibition mainly concerns down-regulated genes allow us to consider prospective synthetically lethal (Nijman, 2011) KALRN interactions. More than $10 \%$ of these "mis-expressed" genes were identified previously as upregulated by DNMT1 inhibition in ADRN NB (Henrich et al, 2016), suggesting that epigenetic drugs (DNMT- and EZH2 inhibitors) warrant further evaluation in the context of kalirin-GEF1-inhibited ADRN-type cells. Whether the combination of kalirin-GEF1 inhibitors with the drugs has a synergistic effect should be explored in a physiologically relevant environment. Because many humanspecific transcripts are likely to impact the phenotypes we observed, we prioritise organotypic 3-D cell culture and tumor slice culture (Sivakumar et al, 2019) as well as ex vivo DTC treatment for further drug screening. Finally, we think that NB is not the only cancer type affected by NUC. Small cell lung cancer, pheochromocytomas and medulloblastomas express genes required for NUC migrations and might also spread nucleokinetically.

\section{Materials and Methods}

\section{Patients}

Neuroblastoma tumor samples were collected before any cytoreductive treatment, snap-frozen, and stored at $-80^{\circ} \mathrm{C}$ until RNA or DNA isolation. Written informed consent was obtained from patients' parents for tissue sampling. Genomic MYCN status was assessed in the reference laboratories of the German Neuroblastoma trial in Cologne and Heidelberg.

\section{Antibodies and reagents}

Rabbit anti-kalirin-SP antibody (MBS821543), goat-kalirin-STYV antibody (ab52012), and rabbit kalirin-GEF2 antibody (TA590559) were purchased from MyBioSource, Abcam, and Acris. Rabbit anti-TRIO antibody (A304269A) was from Bethyl Laboratories, rabbit anti-TIAM1 antibody (ST1070) was from Calbiochem, rabbit anti-SOX11 was from Millipore, mouse (GTU88), and rabbit anti- $y$-tubulin (DQ-19) antibodies were from SigmaAldrich. The rabbit polyclonal antibody, SOX11-PAb, was custom made (Absea Biotechnology) against the immunogenic peptide $\mathrm{p}$-SOX11 $1^{\mathrm{c} \text {-term }}$ DDDDDDDDDELQLQIKQEPDEEDEEPPHQQLLQPPGQQPSQLLRRYNVAKVPASPTLSSSAESPEGASLYDEVRAGATSGAGGGSRLYYSFKNITKQHPPPLAQPALSPASSRSVSTSSS (Decaesteker et al, 2020 Preprint). Mouse 
anti-Golgi apparatus (NB37-100) was from Merck Millipore. Rabbit antiRAC1/2/3 (2465), rabbit anti centrin-2 (2091), rabbit anti-DCX (4604), and rabbit anti- $\beta$ III-tubulin (D71G9) antibodies were purchased from Cell Signalling. Mouse anti-RAC1 antibody (\#ARC03) was from Cytoskeleton. Protein G-Agarose was purchased from Santa Cruz Biotechnologies (Protein A/G-Agarose; sc-2003). $\beta$-actin antibody and sheep anti-goat HRP-conjugated antibody were from Santa Cruz Biotechnologies. HRPconjugated antibodies against mouse or rabbit and the Cy3-conjugated anti-goat antibody were obtained from Jackson Immunoresearch Laboratories. The Alexa 488-conjugated goat anti-rabbit antibody (ab150077) and Cy5.5-conjugated goat anti-mouse (ab6947) were obtained from Abcam. RA and Calcein AM were purchased from Sigma-Aldrich. RAC1 inhibitor NSC23766 and cytochalasin B were purchased from Sigma-Aldrich. TRIO/kalirin-GEF1 inhibitors, ITX3 (2-[(2,5-Dimethyl-1-phenyl-1H-pyrrol-3-yl)methylene]-thiazolo[3,2a]benzimidazol-3(2H)-one), and NPPD (1-(3-nitrophenyl)-1H-pyrrole2,5-dione), were purchased from Sigma-Aldrich and Matrix Scientific, respectively. $\mathrm{RHOA}$ inhibitor, rhosin, was from Sigma-Aldrich. All the reagents were first dissolved in the medium before application to the cells. ROCK inhibitor, Y27632, was obtained from StemCells Technologies. Colcemid was from Thermo Fisher Scientific.

\section{Cell culture and cell viability assay}

Neuroblastoma cell lines were maintained in RPMI1640 supplemented with $10 \%$ fetal bovine serum. NB-S-124 cell line was established from infiltrated bone marrow aspirate from 1-y-old patient (established by Dr. F Westermann; Lodrini et al, 2013) and was grown in DMEM/F12 (Thermo Fisher Scientific) with 6\% NeuroCult SM1 Neuronal Supplement (StemCells Technologies), $20 \mathrm{ng} /$ $\mathrm{ml} \mathrm{bFGF} \mathrm{(Promocell)} \mathrm{and} 5 \mathrm{ng} / \mathrm{ml}$ EGF (Promocell) at $37^{\circ} \mathrm{C}, 5 \% \mathrm{CO}_{2}$ using gelatin-coated cellware. Spheroids were generated by coating 96 well flat bottom plates with 1\% agarose. 5,000 cells were seeded per each well and allowed to form spheroids for $72 \mathrm{~h}$. For cell viability Alamar Blue (AbD Serotec) was used according manufacturer's instructions. Fluorescence was detected using the FluorStar Optima microplate fluorescence reader (BMG Labtech).

\section{DNA constructs, siRNAs and siRNA transfection}

Human kalirin-7 (NM_003947) pENTR223.1 entry clone was retrieved from DKFZ clone repository (DKFZ). Kalirin-7 cDNA was subcloned using Gateway technology (Thermo Fisher Scientific) into the pTREX31 vector (Thermo Fisher Scientific). Stable SOX11 expression was achieved with transducing SOX11 cDNA sequences were into pLenti6.3/TO/V5-Dest (Thermo Fisher Scientific) and pLVX-Tet3G (Clontech). For siRNA transfection, cells were seeded in six-well tissue culture plates $24 \mathrm{~h}$ before transfection. $100 \mathrm{nM}$ of siRNA nontargeting control (siRNA NTC; Dharmacon) or siRNA SOX11 (Dharmacon) were transiently transfected using DharmaFect 2 (Thermo Fisher Scientific) according to the manufacturer's guidelines. SOX11 expression was induced by doxycycline addition $(0.1 \mu \mathrm{g} / \mathrm{ml})$; and induction was assessed by WB for SOX11 (Decaesteker et al, 2020 Preprint). mCherry-gamma-tubulin-17, CyPet-RAC1, and DCX-RFP (Tanaka et al, 2004) constructs were from Addgene repository. pFUCCI G1 Orange construct was from MBL. For knockdown experiments with siRNAs (20 $\mu \mathrm{M}$ stock; $10 \mathrm{nM}$ final concentration),
Lipofectamine RNAiMAX reagent (Life Technologies) was used according to manufacturer's instructions. KALRN (sc-18592), LIS1 (sc-35814), DCX (sc-35214), HNRNPK (sc-38282), and DISC1 (sc-60539) were purchased from Santa Cruz Biotechnologies. DCX siRNA used in the DCX-RFP experiments was from Thermo Fisher Scientific. RAC1 siRNAs were prepared by chemical synthesis (Sigma-Aldrich) using sequences provided by Kutys and Yamada (2014). ROCK1 SiRNA (SIHK1980; SIHK1981) and ROCK2 SiRNA (SIHK1983; SIHK1984) were purchased from Sigma-Aldrich, SOX11 siRNA was from Thermo Fisher Scientific. Transfection with a Silencer Select Negative Control siRNA \#1 (Thermo Fisher Scientific) was used as controls.

\section{Real time quantitative reverse transcription PCR (qRT-PCR) and reverse transcription RT-PCR}

Real-time qRT-PCR was performed by using the Applied Biosystems 7000 Sequence Detection system (Applied Biosystems). Amplification of cDNA by real-time PCR was quantified using SYBR Green (Thermo Fisher Scientific) as previously described (Afanasyeva et al, 2011) with the following QuantiTect Primer Assay: LIS1 (QT00013447), DCX (QT00008540) and SOX11 (QT00221466). ROCK1 primers were retrieved from PrimerDB (Pattyn et al, 2003). ROCK2 primers were as designed by Li et al (2015). RT-PCR for kalirin-12, kalirin-9, and DUET 3'-UTR was performed as described previously (Mains et al, 2011) using the primers homologous to mouse Kalrn.

\section{cDNA sequencing}

PCR fragments were purified using the QIAquick PCR Purification Kit (QIAGEN). Sequencing of RT-PCR products was performed with primers used in the PCR reaction (Mains et al, 2011). FinchTV (Geospiza Inc.) was used to visualize electrophoregrams.

\section{D migration (exclusion) assay}

Neuroblastoma cells were seeded into 96-well plates (Platypus) coated with fibronectin/collagenIV and grown to confluence. A single wound was then created in the cell monolayer and migration of the cells from the edge of the wound was analysed. The area between the wound edges was measured using ImageJ software (National Institutes of Health; NIH). The area of the wound in the control cells was set as $100 \%$, and the relative change was calculated as a percentage of the initial area.

\section{Time-lapse imaging}

Time-lapse images of living cells were captured using Ti-e Eclipse (Nikon) equipped with an incubation chamber. Neuroblastoma cell lines were cultured in RPMI-1640 medium (Thermo Fisher Scientific) as described above on plastic-bottomed chamber (Ibidi) precoated with Collagen IV/Fibronectin/Laminin (Sigma-Aldrich). Cells were analysed with a 10×, 20× and 40× objective lens. Optimal time-lapse intervals (IMR-32; $5 \mathrm{~min}$; median velocity: $0.91 \mu \mathrm{m} / \mathrm{min}$; SH-EP; $15 \mathrm{~min}$; median velocity: $0.3 \mu \mathrm{m} / \mathrm{min}$ ) were chosen to capture nucleokinetic or mesenchymal migration. Imaging data were stored as files in NIS-Elements software (Nikon). Object segmentation was performed using ilastik (Sommer et al, 2011). The time- intervals 
were assembled by ImageJ and analysed using "Manual Tracking Tool," "Nucleus J" and "Mosaic" plugins. For noise correction of NUC events, the median value of $0.12 \mu \mathrm{m}$ derived from analysis of nuclei in sessile IMR-32 cells (migration speed $<0.05 \mu \mathrm{m} / \mathrm{min}$ ) was implemented.

\section{GTPase pulldown}

Rho GTPase activation was analysed by a modification of a protocol described previously (Ren et al, 1999). Cells were washed with PBS, placed on ice, and scraped into lysis buffer (25 mM Hepes, pH 7.3, 150 $\mathrm{mM} \mathrm{NaCl}, 100 \mathrm{mM} \mathrm{NaCl}, 2 \mathrm{mM} \mathrm{MgCl}$, and 1\% Nonidet P-40 supplemented with protease inhibitors cocktail) and then lysed. Insoluble material was removed by centrifugation for $10 \mathrm{~min}$ at $9,500 \mathrm{~g}$. Lysates were incubated with $1 \mu \mathrm{g}$ of PAK-PBD or RhotekinRBD (Cytoskeleton) for $16 \mathrm{~h}$ at $4^{\circ} \mathrm{C}$. Beads were washed, and the proteins were eluted with Laemmli sample buffer and analysed by immunoblotting with anti-RAC1 antibody according to the manufacturer's instructions.

\section{Immunocytochemistry}

Cells growing on slides were fixed with $4 \%$ paraformaldehyde in PBS or ice-cold methanol for tubulin/Golgi Apparatus-compatible staining, washed with PBS, and permeabilized with $0.1 \%$ Triton X-100. After blocking with $5 \%$ fetal bovine serum and $1 \%$ BSA, the slides were incubated with primary antibodies against kalirin-PH and kalirin-STYV, TRIO, TIAM1, $\beta$ IIItubulin, $\gamma$-tubulin, and Golgi apparatus, washed with PBS and incubated with secondary antibodies: Cy3-conjugated donkey anti-goat, Alexa Fluor 488-conjugated sheep anti-rabbit or Cy5.5-conjugated goat anti-mouse. Triple immunostainings with anti-kalirin-STYV antibody were processed with Cy3-conjugated donkey anti-goat antibody first. Alexa Fluor 555phalloidin staining was performed according to the manufacturer's instructions (Thermo Fisher Scientific). The slides were counterstained with DAPI $(1 \mu \mathrm{g} / \mathrm{ml})$ for $5 \mathrm{~min}$. Phalloidin-stained cells were photographed within $30 \mathrm{~min}$ after the staining procedure.

\section{Western blotting}

Western blotting was performed as described previously (Afanasyeva et al, 2011). Briefly, the whole cells were prepared in a buffer containing 7 M urea, 1\% Triton X-100, 100 mM DTT, 20 mM Tris-HCl, pH 8.5. Protein concentrations were determined by Bradford assay (BioRad), and $50 \mu$ g protein lysate were separated per lane on either $7.5 \%$ or $12 \%$ PAGE gels then transferred to nitrocellulose membranes (Protran). Membranes were incubated with the appropriate antibodies, and the bands were visualized using the ECL system (Pierce). Images were captured with a CCD camera (Vilber Lourmat).

\section{Chromatin immunoprecipitation DNA-sequencing (ChIP-seq) of histone modifications}

Formaldehyde cross-linking of cells, cell lysis, sonication, chromatin immunoprecipitation (IP) procedure, and library preparation were performed as described previously (Blecher-Gonen et al, 2013), starting with $\sim 4 \times 10^{6}$ cells $\left(1 \times 10^{6}\right.$ cells per individual IP). Direct cell lysis for each sample was achieved by incubation for 30 min in $950 \mu \mathrm{l} \mathrm{RIPA} \mathrm{I} \mathrm{on} \mathrm{ice} \mathrm{(10} \mathrm{mM} \mathrm{Tris-HCl,} \mathrm{pH} \mathrm{8.0,} 1$ mM EDTA, pH 8.0, $140 \mathrm{mM} \mathrm{NaCl}, 0.2 \%$ SDS, and 0.1\% DOC). Tissue disruption, formaldehyde fixation, and sonication of tumor material were performed according to a previously published protocol (Dahl \& Collas, 2008). Approximately $30 \mathrm{mg}$ of fresh-frozen tumor tissue was used per individual ChIP-seq experiment. All subsequent steps were performed analogous to cell line experiments. The Bioruptor Plus sonication device (Diagenode) was used for high intensity sonication for 30-60 min each with $30 \mathrm{~s}$ on and $30 \mathrm{~s}$ off intervals. For the IP antibodies for H3K4me3 (\#ab8580; Abcam), H3K36me3 (\#ab9050; Abcam) and (\#39155; Active Motif) were used. Library preparation was performed using the NEBNext Ultra DNA Library Prep Kit (New England Biolabs) according to the manufacturer's protocol. Samples were mixed in equal molar ratios and sequenced on an Illumina sequencing platform.

\section{ChIP-seq analysis}

Single-end reads were aligned to the hg19 genome using Bowtie2 (version 2.1.0). Only uniquely aligned reads were kept. Binary Alignment Map files of aligned reads were further processed using the deepTools3 (Ramirez et al, 2014). Input files were subtracted from the treatment files using the bamCompare tool, applying the signal extraction scaling method for normalization of signal to noise. Resulting signals were normalized to a mean $1 \times$ coverage to produce signal (bigWig) files. Peaks were called using the MACS 1.4 tool using default parameters.

\section{Differential gene expression and gene set enrichment analyses}

mRNA gene expression analyses was performed within R2: genomics analysis and visualization platform (http://r2.amc.nl). We used publicly available gene expression omnibus (GEO) datasets: Neuroblastoma custom/AG44 (GEO: gse49710, n = 498; platform: ag44kcwolf), Neuroblastoma RPM/SEQC (GEO: gse62564, $n=498$; platform: seqcnb1), Neuroblastoma Versteeg (GEO: gse16476, $n=88$ ), Neuroblastoma Hiyama (GEO: gse13136; $n=30$ ), and Normal Peripheral Glial Cells (GEO: gse99933; $n=376$ [E13.5], $n=384$ [E12.5]). Differentially expressed genes between clinically-relevant dichotomies in primary neuroblastoma (gse49710) were obtained by GEO2R tool (http://www.ncbi.nlm.nih.gov/geo/geo2r). Gene correlation graphs, "correlated with a single gene" data, "Parametric Gene set Enrichment" data were extracted from the R2 database. Venn diagrams were generated with the GeneVenn an BioVenn web applications (Hulsen et al, 2008). Gene set enrichment was analysed with GSEA (Subramanian et al, 2005).

\section{Microarray analysis}

Gene expression profiles from SK-N-BE(2)c treated with vehicle and RA were generated as two one-color replicates using the wholegenome oligonucleotide microarray platform from Agilent (Agilent Technologies) as previously described (Oberthuer et al, 2006; Westermann et al, 2008). Raw microarray data were normalized using quantile normalization. Expression ratios are given as the mean of two replicates. 


\section{RNA-seq procedure}

RNA was depleted from ribosomal RNAs using the Ribo-Zero rRNA Removal Kit (Illumina) according to the manufacturer's protocol. RNA libraries were prepared using the NEBNext Ultra Directional RNA Library Prep Kit for Illumina (New England Biolabs) according to the manufacturer's protocol with the following changes: RNA was fragmented for $20 \mathrm{~min}$ at $94^{\circ} \mathrm{C}$ followed by first strand CDNA synthesis for $10 \mathrm{~min}$ at $25^{\circ} \mathrm{C}, 50 \mathrm{~min}$ at $42^{\circ} \mathrm{C}$, and $15 \mathrm{~min}$ at $70^{\circ} \mathrm{C}$. Size selection of adapter-ligated DNA was performed with a bead:DNA ratio of 0.4 (AMPure XP beads; Beckman Coulter) removing index primer and short fragments. Quality, quantity, and sizing ( $320 \mathrm{bp}$ ) of the RNA library were analysed using a DNA High Sensitivity DNA chip run on a 2100 Bioanalyzer (Agilent Technologies). Libraries were sequenced (50 bases single-end) on the Illumina sequencing platform. The normalized gene expression values were grouped into controls and intervention samples. Fold-change was calculated both by means and trimeans $(n=3)$ and followed by a $\log _{2}$ transformation. Statistical significance was investigated by the rank-based Kruskal--Wallis test (https://www.jstor.org/stable/ 2280779?seq=1\#page_scan_tab_contents) under no assumption of the underlying distribution. No filtering of data was applied based on fold-change or $P$-value cutoffs because of the low sample sizes available in the experiment.

\section{RNA-seq gene profile}

Additional tumor RNA-seq data subset $(n=27)$ from previous NB study (Henrich et al, 2016) was applied to perform KALRN exon expression analysis. The reads were aligned to hg19 reference using STAR 2.5.2 tool (Dobin et al, 2013). Further per exon gene counts were computed using adjusted annotation gencode v19 and differential expression analysis along with figure generation was performed using DEXseq R package (Anders et al, 2012).

\section{Data Availability}

All sequencing data from this publication were deposited to the European Genome-phenome Archive (Lappalainen et al, 2015), the identifier EGAS00001005023.

\section{Supplementary Information}

Supplementary Information is available at https://doi.org/10.26508/lsa. 201900332.

\section{Acknowledgements}

We thank Elisa Wecht, Young-Gui Park, Jochen Kreth, Steffen Bannert, Erika Kuchen, Ines Gräßer and Fanny de Vloed for technical support. This work was supported by the e:Med initiative (SYSMED-NB, grant no. 01ZX1307D to $F$ Westermann) the German Cancer Consortium (DKTK) Joint Funding program, the ERACoSysMed grant INFER-NB to F Westermann, the German Cancer Research Center (DKFZ) intramural program for interaction projects (NCT3.0
ENHANCE to F Westermann) and the DKFZ-Heidelberg Center for Personalized Oncology (HIPO) \& National Center for Tumor Diseases (NCT) Precision Oncology Program (F Westermann).

\section{Author Contributions}

EA Afanasyeva: conceptualization, data curation, software, formal analysis, investigation, visualization, methodology, and writing-original draft, review, and editing.

M Gartlgruber: conceptualization, data curation, and investigation. T Ryl: investigation and writing-original draft.

B Decaesteker: investigation and visualization.

G Denecker: investigation, visualization, and writing-original draft. $G$ Mönke: formal analysis.

UH Toprak: data curation and formal analysis.

A Florez: investigation.

A Torkov: data curation and investigation.

D Dreidax: conceptualization and data curation.

C Herrmann: data curation and formal analysis.

K Okonechnikov: data curation and formal analysis.

$S$ Ek: investigation.

AK Sharma: formal analysis.

V Sagulenko: investigation.

F Speleman: conceptualization, data curation, and supervision.

K-O Henrich: data curation and writing-original draft.

F Westermann: conceptualization, resources, data curation, and supervision.

\section{Conflict of Interest Statement}

The authors declare that they have no conflict of interest.

\section{References}

Afanasyeva EA, Hotz-Wagenblatt A, Glatting KH, Westermann F (2008) New miRNAs cloned from neuroblastoma. BMC Genomics 9: 52. doi:10.1186/ 1471-2164-9-52

Afanasyeva EA, Mestdagh P, Kumps C, Vandesompele J, Ehemann V, Theissen J, Fischer M, Zapatka M, Brors B, Savelyeva L, et al (2011) MicroRNA miR885-5p targets CDK2 and MCM5, activates p53 and inhibits proliferation and survival. Cell Death Differ 18: 974-984. doi:10.1038/ cdd.2010.164

Al-Shammri S, Guberman A, Hsu E (1992) Neuroblastoma and fetal exposure to phenytoin in a child without dysmorphic features. Can J Neurol Sci 19: 243-245. doi:10.1017/s0317167100042347

Anders S, Reyes A, Huber W (2012) Detecting differential usage of exons from RNA-seq data. Genome Res 22: 2008-2017. doi:10.1101/gr.133744.111

Backer S, Hidalgo-Sánchez M, Offner N, Portales-Casamar E, Debant A, Fort P, Gauthier-Rouvière C, Bloch-Gallego E (2007) Trio controls the mature organization of neuronal clusters in the hindbrain. J Neurosci 27: 10323-10332. doi:10.1523/jneurosci.1102-07.2007

Bakheet T, Hitti E, Khabar KSA (2018) ARED-plus: An updated and expanded database of AU-rich element-containing mRNAs and pre-mRNAs. Nucleic Acids Res 46: D218-D220. doi:10.1093/nar/gkx975

Barbash S, Simchovitz A, Buchman AS, Bennett DA, Shifman S, Soreq H (2017) Neuronal-expressed microRNA-targeted pseudogenes compete with coding genes in the human brain. Transl Psychiatry 7: e1199. doi:10.1038/tp.2017.163 
Baudoin JP, Viou L, Launay PS, Luccardini C, Espeso Gil S, Kiyasova V, Irinopoulou T, Alvarez C, Rio JP, Boudier T, et al (2012) Tangentially migrating neurons assemble a primary cilium that promotes their reorientation to the cortical plate. Neuron 76: 1108-1122. doi:10.1016/ j.neuron.2012.10.027

Becker J, Fröhlich J, Perske C, Pavlakovic H, Wilting J (2012) Reelin signalling in neuroblastoma: Migratory switch in metastatic stages. Int J Oncol 41: 681-689. doi:10.3892/ijo.2012.1488

Benevento M, Iacono G, Selten M, Ba W, Oudakker A, Frega M, Keller J, Mancini R, Lewerissa E, Kleefstra T, et al (2016) Histone methylation by the Kleefstra syndrome protein EHMT1 mediates homeostatic synaptic scaling. Neuron 91: 341-355. doi:10.1016/j.neuron.2016.06.003

Bergsland M, Ramsköld D, Zaouter C, Klum S, Sandberg R, Muhr J (2011) Sequentially acting Sox transcription factors in neural lineage development. Genes Dev 25: 2453-2464. doi:10.1101/gad.176008.111

Bid HK, Roberts RD, Manchanda PK, Houghton PJ (2013) RAC1: An emerging therapeutic option for targeting cancer angiogenesis and metastasis. Mol Cancer Ther 12: 1925-1934. doi:10.1158/1535-7163.mct-13-0164

Biegel JA, White PS, Marshall HN, Fujimori M, Zackai EH, Scher CD, Brodeur GM, Emanuel BS (1993) Constitutional 1p36 deletion in a child with neuroblastoma. Am J Hum Genet 52: 176-182.

Blangy A, Bouquier N, Gauthier-Rouvière C, Schmidt S, Debant A, Leonetti JP, Fort P (2006) Identification of TRIO-GEFD1 chemical inhibitors using the yeast exchange assay. Biol Cell 98: 511-522. doi:10.1042/ bc20060023

Blecher-Gonen R, Barnett-Itzhaki Z, Jaitin D, Amann-Zalcenstein D, LaraAstiaso D, Amit I (2013) High-throughput chromatin immunoprecipitation for genome-wide mapping of in vivo proteinDNA interactions and epigenomic states. Nat Protoc 8: 539-554. doi:10.1038/nprot.2013.023

Boeva V, Louis-Brennetot C, Peltier A, Durand S, Pierre-Eugène C, Raynal V, Etchevers HC, Thomas S, Lermine A, Daudigeos-Dubus E, et al (2017) Heterogeneity of NB cell identity defined by transcriptional circuitries. Nat Genet 49: 1408-1413. doi:10.1038/ng.3921

Bouquier N, Vignal E, Charrasse S, Weill M, Schmidt S, Léonetti JP, Blangy A, Fort P (2009) A cell active chemical GEF inhibitor selectively targets the Trio/RhoG/RAC1 signaling pathway. Chem Biol 16: 657-666. doi:10.1016/j.chembiol.2009.04.012

Brabletz T (2012) EMT and MET in metastasis: Where are the cancer stem cells? Cancer Cell 22: 699-701. doi:10.1016/j.ccr.2012.11.009

Brodeur GM, Bagatell R (2014) Mechanisms of neuroblastoma regression. Nat Rev Clin Oncol 11: 704-713. doi:10.1038/nrclinonc.2014.168

Carabalona A, Hu DJ, Vallee RB (2016) KIF1A inhibition immortalizes brain stem cells but blocks BDNF-mediated neuronal migration. Nat Neurosci 19: 253-262. doi:10.1038/nn.4213

Carr J, Bell E, Pearson AD, Kees UR, Beris H, Lunec J, Tweddle DA (2006) Increased frequency of aberrations in the p53/MDM2/p14(ARF) pathway in neuroblastoma cell lines established at relapse. Cancer Res 16: 2138-2145. doi:10.1158/0008-5472.can-05-2623

Caspi M, Atlas R, Kantor A, Sapir T, Reiner O (2000) Interaction between LIS1 and doublecortin, two lissencephaly gene products. Hum Mol Genet 9: 2205-2213. doi:10.1093/oxfordjournals.hmg.a018911

Chen L, Alexe G, Dharia NV, Ross L, Iniguez AB, Conway AS, Wang EJ, Veschi V, Lam N, Qi J, et al (2018) CRISPR-Cas9 screen reveals a MYCN-amplified neuroblastoma dependency on EZH2. I Clin Invest 128: 446-462. doi:10.1172/JC190793

Chen L, Iraci N, Gherardi S, Gamble LD, Wood KM, Perini G, Lunec I, Tweddle DA (2010) p53 is a direct transcriptional target of MYCN in neuroblastoma. Cancer Res 70: 1377-1388. doi:10.1158/0008-5472.can-09-2598

Cheng L, Yang T, Kuang Y, Kong B, Yu S, Shu H, Zhou H, Gu J (2014) MicroRNA23a promotes neuroblastoma cell metastasis by targeting CDH1. Oncol Lett 7: 839-845. doi:10.3892/ol.2014.1794
Colak D, Ji SJ, Porse BT, Jaffrey SR (2013) Regulation of axon guidance by compartmentalized nonsense-mediated mRNA decay. Cell 153: 1252-1265. doi:10.1016/j.cell.2013.04.056

Dahl JA, Collas P (2008) A rapid micro chromatin immunoprecipitation assay (microChIP). Nat Protoc 3: 1032-1045. doi:10.1038/nprot.2008.68

Decaesteker B, Louwagie A, Loontiens S, De Vloed F, Roels J, Vanhauwaert S, De Brouwer S, Sanders E, Denecker G, D'haene E, et al (2020) SOX11 is a lineage-dependency factor and master epigenetic regulator in neuroblastoma. bioRxiv doi:10.1101/2020.08.21.261131. (Preprint posted August 21, 2020).

Deckwerth TL, Elliot JL, Knudson CM, Johnson EM Jr., Snider WD, Korsmeyer S, (1996) BAX is required for neuronal death after trophic factor deprivation and during development. Neuron 17: 401-411. doi:10.1016/ s0896-6273(00)80173-7

Delloye-Bourgeois C, Castellani V (2019) Hijacking of embryonic programs by neural crest-derived neuroblastoma: From physiological migration to metastatic dissemination. Front Mol Neurosci 12: 52. doi:10.3389/ fnmol.2019.00052

Deo AJ, Cahill ME, Li S, Goldszer I, Henteleff R, Vanleeuwen JE, Rafalovich I, Gao R, Stachowski EK, Sampson AR, et al (2012) Increased expression of kalirin-9 in the auditory cortex of schizophrenia subjects: Its role in dendritic pathology. Neurobiol Dis 45: 796-803. doi:10.1016/ j.nbd.2011.11.003

Deuel TA, Liu JS, Corbo JC, Yoo SY, Rorke-Adams LB, Walsh CA (2006) Genetic interactions between doublecortin and doublecortin-like kinase in neuronal migration and axon outgrowth. Neuron 49: 41-53. doi:10.1016/j.neuron.2005.10.038

Distel M, Hocking JC, Volkmann K, Köster RW (2010) The centrosome neither persistently leads migration nor determines the site of axonogenesis in migrating neurons in vivo. J Cell Biol 191: 875-890. doi:10.1083/ jcb.201004154

Dobin A, Davis CA, Schlesinger F, Drenkow J, Zaleski C, Jha S, Batut P, Chaisson M, Gingeras TR (2013) STAR: Ultrafast universal RNA-seq aligner. Bioinformatics 29: 15-21. doi:10.1093/bioinformatics/bts635

Dobyns WB, Mirzaa G, Christian SL, Petras K, Roseberry J, Clark GD, Curry C), McDonald-McGinn D, Medne L, Zackai E, et al (2010) Consistent chromosome abnormalities identify novel polymicrogyria loci in 1p36.3, 2p16.1-p23.1, 4q21.21-q22.1, 6q26-q27, and 21q2. Am J Med Genet A 146A: 1637-1654. doi:10.1002/ajmg.a.32293

Dzieran J, Rodriguez Garcia A, Westermark UK, Henley AB, Eyre Sánchez E, Träger C, Johansson HJ, Lehtiö J, Arsenian-Henriksson M (2018) MYCNamplified neuroblastoma maintains an aggressive and undifferentiated phenotype by deregulation of estrogen and NGF signaling. Proc Natl Acad Sci U S A 115: E1229-E1238. doi:10.1073/ pnas. 1710901115

El Waly B, Mignon-Ravix C, Cacciagli P, Buhler E, Bruria ben Zeev B, Villard L (2020) Molecular characterization of a 1p36 chromosomal duplication and in utero interference define ENO1 as a candidate gene for polymicrogyria. Eur J Hum Genet 28: 1703-1713. doi:10.1038/s41431-0200659-z

Evangelisti C, Florian MC, Massimi I, Dominici C, Giannini G, Galardi S, Buè MC, Massalini S, McDowell HP, Messi E, et al (2009) MiR-128 up-regulation inhibits Reelin and DCX expression and reduces neuroblastoma cell motility and invasiveness. FASEB / 23: 4276-4287. doi:10.1096/fj.09134965

Ferraro F, Ma X-M, Sobota JA, Eipper BA, Mains RA (2007) Kalirin/Trio Rho guanine nucleotide exchange factors regulate a novel step in secretory granule maturation. Mol Biol Cell 18: 4813-4825. doi:10.1091/ mbc.e07-05-0503

Flynt AS, Lai EC (2008) Biological principles of microRNA-mediated regulation: Shared themes amid diversity. Nat Rev Genet 9: 831-842. doi:10.1038/nrg2455 
Furlan A, Dyachuk V, Kastriti ME, Calvo-Enrique L, Abdo H, Hadjab S, Chontorotzea T, Akkuratova N, Usoskin D, Kamenev D, et al (2017) Multipotent peripheral glial cells generate neuroendocrine cells of the adrenal medulla. Science 357: eaal3753. doi:10.1126/ science.aal3753

Gandalovičová A, Rosel D, Fernandes M, Veselý P, Heneberg P, Čermák V, Petruželka L, Kumar S, Sanz-Moreno V, Brábek J (2017) Migrastaticsanti-metastatic and anti-invasion drugs: Promises and challenges. Trends Cancer 3: 391-406. doi:10.1016/j.trecan.2017.04.008

Gao Y, Dickerson JB, Guo F, Zheng J, Zheng Y (2004) Rational design and characterization of a rac GTPase-specific small molecule inhibitor. Proc Natl Acad Sci U S A 101: 7618-7623. doi:10.1073/pnas.0307512101

Garcia I, Mayol G, Ríos J, Domenech G, Cheung N-KV, Oberthuer A, Fischer M, Maris JM, Brodeur GM, Hero B, et al (2012) Three-gene expression signature model for risk stratification of patients with neuroblastoma. Clin Cancer Res 18: 2012-2023. doi:10.1158/1078-0432.ccr-11-2483

Gartlgruber M, Sharma AK, Quintero A, Dreidax D, Jansky S, Park Y-G, Kreth S, Meder J, Doncevic D, Saary P, et al (2021) Super enhancers define regulatory subtypes and cell identity in neuroblastoma. Nat Cancer 2: 114-128. doi:10.1038/s43018-020-00145-w

Gibert B, Delloye-Bourgeois C, Gattolliat CH, Meurette O, Le Guernevel S, Fombonne J, Ducarouge B, Lavial F, Bouhallier F, Creveaux M, et al (2014) Regulation by miR181 family of the dependence receptor CDON tumor suppressive activity in neuroblastoma. J Natl Cancer Inst 106: dju318. doi:10.1093/jnci/dju318

Haas G, Cetin S, Messmer M, Chane-Woon-Ming B, Terenzi O, Chicher J, Kuhn L, Hammann P, Pfeffer S (2016) Identification of factors involved in target RNA-directed microRNA degradation. Nucleic Acids Res 44: 2873-2887. doi:10.1093/nar/gkw040

Häming D, Simões-Costa M, Uy B, Valencia J, Sauka-Spengler T, BronnerFraser M (2011) Expression of sympathetic nervous system genes in lamprey suggests their recruitment for specification of a new vertebrate feature. PLoS One 6: e26543. doi:10.1371/ journal.pone. 0026543

Hansel DE, Quiñones ME, Ronnett GV, Eipper BA (2001) Kalirin, a GDP/GTP exchange factor of the Dbl family, is localized to nerve, muscle, and endocrine tissue during embryonic rat development. J Histochem Cytochem 49: 833-844. doi:10.1177/002215540104900704

Hartomo TB, Kozaki A, Hasegawa D, Van Huyen Pham T, Yamamoto N, Saitoh A, Ishida T, Kawasaki K, Kosaka Y, Ohashi H, et al (2013) Minimal residual disease monitoring in NB patients based on the expression of a set of real-time RT-PCR markers in tumor-initiating cells. Oncol Rep 29: 1629-1636. doi:10.3892/or.2013.2286

Heim B (2014) SOX11 interactome analysis: Implication in transcriptional control and neurogenesis. (Doctoral Dissertation). Retrieved from https://publikationen.uni-tuebingen.de/xmlui/bitstream/handle/ 10900/59876/Dissertation\%20Birgit\%20Heim.pdf.

Henrich KO, Bender S, Saadati M, Dreidax D, Gartlgruber M, Shao C, Herrmann C, Wiesenfarth M, Parzonka M, Wehrmann L, et al (2016) Integrative genome-scale analysis identifies epigenetic mechanisms of transcriptional deregulation in unfavorable neuroblastomas. Cancer Res 76: 5523-5537. doi:10.1158/0008-5472.can-15-2507

Higginbotham H, Eom TY, Mariani LE, Bachleda A, Hirt J, Gukassyan V, Cusack CL, Lai C, Caspary T, Anton ES (2012) Arl13b in primary cilia regulates the migration and placement of interneurons in the developing cerebral cortex. Dev Cell 23: 925-938. doi:10.1016/j.devcel.2012.09.019

Hines TJ, Gao X, Sahu S, Lange MM, Turner JR, Twiss JL, Smith DS (2018) An essential postdevelopmental role for Lis1 in mice. eNeuro 5: ENEURO.0350-17.2018. doi:10.1523/ENEURO.0350-17.2018

Hoshiba Y, Toda T, Ebisu H, Wakimoto M, Yanagi S, Kawasaki H (2016) Sox11 balances dendritic morphogenesis with neuronal migration in the developing cerebral cortex. J Neurosci 36: 5775-5784. doi:10.1523/ jneurosci.3250-15.2016
Hulsen T, de Vlieg J, Alkema W (2008) BioVenn: A web application for the comparison and visualization of biological lists using areaproportional Venn diagrams. BMC Genomics 9: 488. doi:10.1186/14712164-9-488

Iacono G, Dubos A, Méziane H, Benevento M, Habibi E, Mandoli A, Riet F, Selloum M, Feil R, Zhou H, et al (2018) Increased H3K9 methylation and impaired expression of Protocadherins are associated with the cognitive dysfunctions of the Kleefstra syndrome. Nucleic Acids Res 46: 4950-4965. doi:10.1093/nar/gky196

Isidor B, Le Cunff M, Boceno M, Boisseau P, Thomas C, Rival JM, David A, Le Caignec C (2008) Complex constitutional subtelomeric 1 p36.3 deletion/duplication in a mentally retarded child with neonatal neuroblastoma. Eur J Med Genet 51: 679-684. doi:10.1016/ j.ejmg.2008.06.004

Jaffrey SR, Wilkinson MF (2018) Nonsense-mediated RNA decay in the brain: Emerging modulator of neural development and disease. Nat Rev Neurosci 19: 715-728. doi:10.1038/s41583-018-0079-z

Jing Q, Huang S, Guth S, Zarubin T, Motoyama A, Chen J, Di Padova F, Lin SC, Gram H, Han J (2005) Involvement of microRNA in AU-rich elementmediated mRNA instability. Cell 120: 623-634. doi:10.1016/ j.cell.2004.12.038

Jissendi-Tchofo P, Kara S, Barkovich AJ (2009) Midbrain-hindbrain involvement in lissencephalies. Neurology 72: 410-418. doi:10.1212/ 01.wnl.0000333256.74903.94

Johnson RC, Penzes P, Eipper BA, Mains RE (2000) Isoforms of Kalirin, a neuronal $\mathrm{Dbl}$ family member, generated through use of different $5^{\prime}$ and $3^{\prime}$-ends along with an internal translational initiation site. J Biol Chem 275: 19324-19333. doi:10.1074/jbc.m000676200

Jordan VK, Zaveri HP, Scott DA (2015) 1 p36 deletion syndrome: An update. Appl Clin Genet 8: 189-200. doi:10.2147/TACG.S65698

Jung AR, Kim TW, Rhyu IJ, Kim H, Lee YD, Vinsant S, Oppenheim RW, Sun W (2008) Misplacement of Purkinje cells during postnatal development in Bax knock-out mice: A novel role for programmed cell death in the nervous system? J Neurosci 28: 2941-2948. doi:10.1523/jneurosci.389707.2008

Kawauchi T, Chihama K, Nabeshima Y-i, Hoshino M (2003) The in vivo roles of STEF/Tiam1, RAC1 and JNK in cortical neuronal migration. EMBO I 22: 4190-4201. doi:10.1093/emboj/cdg413

Kawauchi T, Nabeshima YI (2019) Growth arrest triggers extra-cell cycle regulatory function in neurons: Possible involvement of $\mathrm{p} 27^{\mathrm{kip} 1}$ in membrane trafficking as well as cytoskeletal regulation. Front Cell Dev Biol 7: 64. doi:10.3389/fcell.2019.00064

Kertesz M, Iovino N, Unnerstall U, Gaul U, Segal E (2007) The role of site accessibility in microRNA target recognition. Nat Genet 39: 1278-1284. doi:10.1038/ng2135

Konjikusic MJ, Yeetong P, Boswell CW, Lee C, Roberson EC, Ittiwut R, Suphapeetiporn K, Ciruna B, Gurnett CA, Wallingford JB, et al (2018) Mutations in Kinesin family member 6 reveal specific role in ependymal cell ciliogenesis and human neurological development. PLOS Genet 14: e1007817. doi:10.1371/journal.pgen.1007817

Kratzer MC, England L, Apel D, Hassel M, Borchers A (2019) Evolution of the Rho guanine nucleotide exchange factors Kalirin and Trio and their gene expression in Xenopus development. Gene Expr Patterns 32: 18-27. doi:10.1016/j.gep.2019.02.004

Kuo PY, Leshchenko VV, Fazzari MJ, Perumal D, Gellen T, He T, Iqbal J, Baumgartner-Wennerholm S, Nygren L, Zhang F, et al (2015) Highresolution chromatin immunoprecipitation (ChIP) sequencing reveals novel binding targets and prognostic role for SOX11 in mantle cell lymphoma. Oncogene 34: 1231-1240. doi:10.1038/onc.2014.44

Kutys ML, Yamada KM (2014) An extracellular-matrix-specific GEF-GAP interaction regulates Rho GTPase crosstalk for 3D collagen migration. Nat Cell Biol 16: 909-917. doi:10.1038/ncb3026 
Kwan KY, Sestan N, Anton ES (2012) Transcriptional co-regulation of neuronal migration and laminar identity in the neocortex. Development 139: 1535-1546. doi:10.1242/dev.069963

Lachmann A, Xu H, Krishnan J, Berger SI, Mazloom AR, Ma'ayan A (2010) ChEA: Transcription factor regulation inferred from integrating genomewide ChIP-X experiments. Bioinformatics 26: 2438-2444. doi:10.1093/ bioinformatics/btq466

LaMonica BE, Lui JH, Hansen DV, Kriegstein AR (2013) Mitotic spindle orientation predicts outer radial glial cell generation in human neocortex. Nat Commun 4: 1665. doi:10.1038/ncomms2647

Lan T, Cheng K, Ren T, Arce SH, Tseng Y (2016) Displacement correlations between a single mesenchymal-like cell and its nucleus effectively link subcellular activities and motility in cell migration analysis. Sci Rep 6: 34047. doi:10.1038/srep34047

Lång E, Połeć A, Lång A, Valk M, Blicher P, Rowe AD, Tфnseth KA, Jackson C), Utheim TP, Janssen LMC, et al (2018) Coordinated collective migration and asymmetric cell division in confluent human keratinocytes without wounding. Nat Commun 9: 3665. doi:10.1038/s41467-01805578-7

Lappalainen I, Almeida-King J, Kumanduri V, Senf A, Spalding AD, Ur-Rehman S, Saunders G, Kandasamy J, Caccamo M, Leinonen R, et al (2015) The European Genome-phenome Archive of human data consented for biomedical research. Nat Genet 47: 692-695. doi:10.1038/ng.3312

Lasorsa VA, Cimmino F, Ognibene M, Mazzocco K, Erminio G, Morini M, Conte M, Iolascon A, Pezzolo A, Capasso M (2020) 19p loss is significantly enriched in older age neuroblastoma patients and correlates with poor prognosis. NPJ Genom Med 5: 18. doi:10.1038/s41525-020-0125-4

Li J-H, Liu S, Zhou H, Qu L-H, Yang J-H (2014) starBase v2.0: Decoding miRNAceRNA, miRNA-ncRNA and protein-RNA interaction networks from large-scale CLIP-Seq data. Nucleic Acids Res 42: D92-D97. doi:10.1093/ nar/gkt1248

Li M, Zhou W, Yuan R, Chen L, Liu T, Huang D, Hao L, Xie Y, Shao J (2015) ROCK2 promotes HCC proliferation by CEBPD inhibition through phosphoGSK3 $\beta / \beta$-catenin signaling. FEBS Lett 589: 1018-2510. doi:10.1016/ j.febslet.2015.03.004

Liu J, Wu X, Zhang H, Pfeifer GP, Lu Q (2017) Dynamics of RNA Polymerase II pausing and bivalent Histone $\mathrm{H} 3$ methylation during neuronal differentiation in brain development. Cell Rep 20: 1307-1318. doi:10.1016/j.celrep.2017.07.046

Liu X, Peng H, Liao W, Luo A, Cai M, He J, Zhang X, Luo Z, Jiang H, Xu L (2018) MiR$181 \mathrm{a} / \mathrm{b}$ induce the growth, invasion, and metastasis of neuroblastoma cells through targeting ABI1. Mol Carcinog 57: 1237-1250. doi:10.1002/ mc.22839

Lo-Castro A, Giana G, Fichera M, Castiglia L, Grillo L, Musumeci SA, Galasso C, Curatolo P (2009) Deletion 2p25.2: A cryptic chromosome abnormality in a patient with autism and mental retardation detected using aCGH. Eur J Med Genet 52: 67-70. doi:10.1016/j.ejmg.2008.09.004

Lodrini M, Oehme I, Schroeder C, Milde T, Schier MC, Kopp-Schneider A, Schulte JH, Fischer M, De Preter K, Pattyn F, et al (2013) MYCN and HDAC2 cooperate to repress miR-183 signaling in neuroblastoma. Nucl Acids Res 41: 6018-6033. doi:10.1093/nar/gkt346

Long AA, Mahapatra CT, Woodruff EA 3rd, Rohrbough J, Leung HT, Shino S, An L, Doerge RW, Metzstein MM, Pak WL, et al (2010) The nonsensemediated decay pathway maintains synapse architecture and synaptic vesicle cycle efficacy. I Cell Sci 123: 3303-3315. doi:10.1242/ jcs.069468

Mains RE, Alam MR, Johnson RC, Darlington DN, Bäck N, Hand TA, Eipper BA (1999) Kalirin: A multifunctional PAM COOH-terminal domain interactor protein, affects cytoskeletal organization and ACTH secretion from AtT-20 cells. J Biol Chem 274: 2929-2937. doi:10.1074/ jbc.274.5.2929
Mains RE, Kiraly DD, Eipper-Mains JE, Ma XM, Eipper BA (2011) Kalrn promoter usage and isoform expression respond to chronic cocaine exposure. BMC Neurosci 12: 20. doi:10.1186/1471-2202-12-20

Mandela P, Yankova M, Conti LH, Ma XM, Grady J, Eipper BA, Mains RE (2012) Kalrn plays key roles within and outside of the nervous system. BMC Neurosci 13: 136. doi:10.1186/1471-2202-13-136

Martini FJ, Valdeolmillos M (2010) Actomyosin contraction at the cell rear drives nuclear translocation in migrating cortical interneurons. J Neurosci 30: 8660-8670. doi:10.1523/jneurosci.1962-10.2010

Matas-Rico E, van Veen M, Leyton-Puig D, van den Berg J, Koster J, Kedziora KM, Molenaar B, Weerts MJA, de Rink I, Medema RH, et al (2016) Glycerophosphodiesterase GDE2 promotes neuroblastoma differentiation through glypican release and is a marker of clinical outcome. Cancer Cell 30: 548-562. doi:10.1016/j.ccell.2016.08.016

May V, Schiller MR, Eipper BA, Mains RE (2002) Kalirin Dbl-homology guanine nucleotide exchange factor 1 domain initiates new axon outgrowths via RhoG-mediated mechanisms. I Neurosci 22: 6980-6990. doi:10.1523/jneurosci.22-16-06980.2002

Merlo P, Frost B, Peng S, Yang YJ, Park PJ, Feany M (2014) p53 prevents neurodegeneration by regulating synaptic genes. Proc Natl Acad Sci U S A 111: 18055-18060. doi:10.1073/pnas.1419083111

Messi E, Florian MC, Caccia C, Zanisi M, Maggi R (2008) Retinoic acid reduces human NB cell migration and invasiveness: Effects on DCX, LIS1, neurofilaments-68 and vimentin expression. BMC Cancer 8: 30. doi:10.1186/1471-2407-8-30

Miller MB, Yan Y, Machida K, Kiraly DD, Levy AD, Wu YI, Lam TT, Abbott T, Koleske AJ, Eipper BA, et al (2017) Brain region and isoform-specific phosphorylation alters kalirin $\mathrm{SH} 2$ domain interaction sites and calpain sensitivity. ACS Chem Neurosci 8: 1554-1569. doi:10.1021/ acschemneuro.7b00076

Mingorance-Le Meur A, O'Connor TP (2009) Neurite consolidation is an active process requiring constant repression of protrusive activity. EMBO J 28: 248-260. doi:10.1038/emboj.2008.265

Mittal A, Sehgal R, Gupta R, Sharma S, Aggarwal KC (2014) Rare association of lissencephaly with Hirschprung's disease. Astrocyte 1: 244-245. doi:10.4103/2349-0977.157775

Molenaar JJ, Koster J, Zwijnenburg DA, van Sluis P, Valentijn LJ, van der Ploeg I, Hamdi M, van Nes J, Westerman BA, van Arkel J, et al (2012) Sequencing of NB identifies chromothripsis and defects in neuritogenesis genes. Nature 483: 589-593. doi:10.1038/nature10910

Moon HM, Youn YH, Pemble H, Yingling J, Wittmann T, Wynshaw-Boris A (2014) LIS1 controls mitosis and mitotic spindle organization via the LIS1-NDEL1-dynein complex. Hum Mol Genet 23: 449-466. doi:10.1093/ hmg/ddt436

Moore KD, Chen R, Cilluffo M, Golden JA, Phelps PE (2012) Lis1 reduction causes tangential migratory errors in mouse spinal cord. I Comp Neurol 520: 1198-1211. doi:10.1002/cne.22768

Mora J, Cheung NK, Chen L, Qin J, Gerald W (2001) Loss of heterozygosity at 19q13.3 is associated with locally aggressive neuroblastoma. Clin Cancer Res 7: 1358-1361.

Mu L, Berti L, Masserdotti G, Covic M, Michaelidis TM, Doberauer K, Merz K, Rehfeld F, Haslinger A, Wegner M, et al (2012) SoxC transcription factors are required for neuronal differentiation in adult hippocampal neurogenesis. J Neurosci 32: 3067-3080. doi:10.1523/ jneurosci.4679-11.2012

Nawabi H, Belin S, Cartoni R, Williams PR, Wang C, Latremolière A, Wang X, Zhu J, Taub DG, Fu X, et al (2015) Doublecortin-like kinases promote neuronal survival and induce growth cone reformation via distinct mechanisms. Neuron 88: 704-719. doi:10.1016/j.neuron.2015.10.005

Nemani L, Barik R, Patnaik AN, Mishra RC, Rao AM, Kapur P (2014) Coffin-Siris syndrome with the rarest constellation of congenital cardiac defects: A case report with review of literature. Ann Pediatr Cardiol 7: 221-226. doi:10.4103/0974-2069.140859 
Nijman S (2011) Synthetic lethality: General principles, utility and detection using genetic screens in human cells. FEBS Lett 585: 1-6. doi:10.1016/ j.febslet.2010.11.024

Nishimura YV, Nabeshima Y-i, Kawauchi T (2017) Morphological and molecular basis of cytoplasmic dilation and swelling in cortical migrating neurons. Brain Sci 7: 87. doi:10.3390/brainsci7070087

Nishimura YV, Shikanai M, Hoshino M, Ohshima T, Nabeshima Y, Ken-ichi Mizutani K, Nagata K, Nakajima K, Kawauchi T (2014) Cdk5 and its substrates, Dcx and $\mathrm{p} 27^{\mathrm{kip} 1}$, regulate cytoplasmic dilation formation and nuclear elongation in migrating neurons. Development 141: 3540-3550. doi:10.1242/dev.111294

Oberthuer A, Berthold F, Warnat P, Hero B, Kahlert Y, Spitz R, Ernestus K, König R, Haas S, Eils R, et al (2006) Customized oligonucleotide microarray gene expression-based classification of NB patients outperforms current clinical risk stratification. J Clin Oncol 24: 5070-5078. doi:10.1200/jco.2006.06.1879

Ohshima T, Ward JM, Huh CG, Longenecker G, Veeranna, Pant HC, Brady RO, Martin LJ, Kulkarni AB (1996) Targeted disruption of the cyclindependent kinase 5 gene results in abnormal corticogenesis, neuronal pathology and perinatal death. Proc Natl Acad Sci U S A 93: 11173-11178. doi:10.1073/pnas.93.20.11173

Oliynyk G, Ruiz-Pérez MV, Sainero-Alcolado L, Dzieran J, Zirath H, GallartAyala H, Wheelock CE, Johansson HJ, Nilsson R, Lehtiö J, et al (2019) MYCN-enhanced oxidative and glycolytic metabolism reveals vulnerabilities for targeting neuroblastoma. iscience 21: 188-204. doi:10.1016/j.isci.2019.10.020

Pattyn F, Speleman F, De Paepe A, Vandesompele J (2003) RTPrimerDB: The real-time PCR primer and probe database. Nucleic Acids Res 31: 122-123. doi:10.1093/nar/gkg011

Pei B, Sisu C, Frankish A, Howald C, Habegger L, Mu XJ, Harte R, Balasubramanian S, Tanzer A, Diekhans M, et al (2012) The GENCODE pseudogene resource. Genome Biol 13: R51. doi:10.1186/gb-2012-13-9r51

Pei D, Luther W, Wang W, Paw BH, Stewart RA, George RE (2013) Distinct NBassociated alterations of $\mathrm{PHOX} 2 \mathrm{~B}$ impair sympathetic neuronal differentiation in zebrafish models. PLoS Genet 9: e1003533. doi:10.1371/journal.pgen.1003533

Petrie RJ, Doyle AD, Yamada KM (2009) Random versus directionally persistent cell migration. Nat Rev Mol Cell Biol 10: 538-549. doi:10.1038/nrm2729

Piens M, Muller M, Bodson M, Baudouin G, Plumier JC (2010) A short upstream promoter region mediates transcriptional regulation of the mouse doublecortin gene in differentiating neurons. BMC Neurosci 11: 64. doi:10.1186/1471-2202-11-64

Poliseno L, Salmena L, Zhang J, Carver B, Haveman WJ, Pandolfi PP (2010) A coding-independent function of gene and pseudogene mRNAs regulates tumour biology. Nature 465: 1033-1038. doi:10.1038/ nature09144

Popp MW, Maquat LE (2018) Nonsense-mediated mRNA decay and cancer. Curr Opin Genet Dev 48: 44-50. doi:10.1016/j.gde.2017.10.007

Potzner MR, Tsarovina K, Binder E, Penzo-Méndez A, Lefebvre V, Rohrer H, Wegner M, Sock E (2010) Sequential requirement of Sox 4 and Sox11 during development of the sympathetic nervous system. Development 137: 775-784. doi:10.1242/dev.042101

Pugh TJ, Morozova O, Attiyeh EF, Asgharzadeh S, Wei JS, Auclair D, Carter SL, Cibulskis K, Hanna M, Kiezun A, et al (2013) The genetic landscape of high-risk neuroblastoma. Nat Genet 45: 279-284. doi:10.1038/ng.2529

Raimondi C, Gianni W, Cortesi E, Gazzaniga P (2010) Cancer stem cells and epithelial-mesenchymal transition: Revisiting minimal residual disease. Curr Cancer Drug Targets 10: 496-508. doi:10.2174/ 156800910791517154
Ramirez F, Dundar F, Diehl S, Gruning BA, Manke T (2014) deepTools: A flexible platform for exploring deep-sequencing data. Nucleic Acids Res 42: W187-W191. doi:10.1093/nar/gku365

Ratner N, Brodeur GM, Dale RC, Schor NF (2016) The "neuro" of neuroblastoma: Neuroblastoma as a neurodevelopmental disorder. Ann Neurol 80: 13-23. doi:10.1002/ana.24659

Ren XD, Kiosses WB, Schwartz MA (1999) Regulation of the small GTP-binding protein Rho by cell adhesion and the cytoskeleton. EMBO J 18: 578-585. doi:10.1093/emboj/18.3.578

Rifatbegovic F, Frech C, Abbasi MR, Taschner-Mandl S, Weiss T, Schmidt WM, Schmidt I, Ladenstein R, Ambros IM, Ambros PF (2018) Neuroblastoma cells undergo transcriptomic alterations upon dissemination into the bone marrow and subsequent tumor progression. Int J Cancer 142: 297-307. doi:10.1002/ijc.31053

Rossel M, Loulier K, Feuillet C, Alonso S, Carroll P (2005) Reelin signaling is necessary for a specific step in the migration of hindbrain efferent neurons. Development 132: 1175-1185. doi:10.1242/dev.01683

Ryl T, Kuchen EE, Bell E, Shao C, Florez A, Mönke G, Gogolin S, Friedrich M, Lamprecht F, Westermann F, et al (2017) Cell-cycle position of single MYC-driven cancer cells dictates their susceptibility to a chemotherapeutic drug. Cell Syst 5: 237-250. doi:10.1016/ j.cels.2017.07.005

Sakakibara A, Ando R, Sapir T, Tanaka T (2013) Microtubule dynamics in neuronal morphogenesis. Open Biol 3: 130061. doi:10.1098/ rsob.130061

Say E, Tay HG, Zhao ZS, Baskaran Y, Li R, Lim L, Manser E (2010) A functional requirement for PAK1 binding to the $\mathrm{KH}(2)$ domain of the fragile $\mathrm{X}$ protein-related FXR1. Mol Cell 38: 236-249. doi:10.1016/ j.molcel.2010.04.004

Schaar BT, McConnell SK (2005) Cytoskeletal coordination during neuronal migration. Proc Natl Acad Sci U S A 102: 13652-13657. doi:10.1073/ pnas.0506008102

Scheckel C, Drapeau E, Frias MA, Park CY, Fak J, Zucker-Scharff I, Kou Y, Haroutunian V, Ma'ayan A, Buxbaum JD, et al (2016) Regulatory consequences of neuronal ELAV-like protein binding to coding and non-coding RNAs in human brain. Elife 5: e10421. doi:10.7554/ elife.10421

Schrier SA, Bodurtha JN, Burton B, Chudley AE, Chiong MA, D'avanzo MG, Lynch SA, Musio A, Nyazov DM, Sanchez-Lara PA, et al (2012) The Coffin-Siris syndrome: A proposed diagnostic approach and assessment of 15 overlapping cases. Am J Med Genet A 158A: 1865-1876. doi:10.1002/ ajmg.a.35415

Sivakumar R, Chan M, Shin JS, Nishida-Aoki N, Kenerson HL, Elemento O, Beltran H, Yeung R, Gujral TS (2019) Organotypic tumor slice cultures provide a versatile platform for immuno-oncology and drug discovery. Oncoimmunology 8: e1670019. doi:10.1080/ 2162402x.2019.1670019

Soldatov R, Kaucka M, Kastriti ME, Petersen J, Chontorotzea T, Englmaier L, Akkuratova N, Yang Y, Häring M, Dyachuk V, et al (2019) Spatiotemporal structure of cell fate decisions in murine neural crest. Science 364: eaas9536. doi:10.1126/science.aas9536

Sommer C, Strähle C, Köthe U, Hamprecht Heidelberg Collaboratory for Image Processing $(\mathrm{HCl})$, University of Heidelberg, Germany FA (2011) Ilastik: Interactive learning and segmentation toolkit. Eighth IEEE International Symposium on Biomedical Imaging (ISBI). In Proceedings doi:10.1109/ISBI.2011.5872394

Squier W, Jansen A (2014) Polymicrogyria: Pathology, fetal origins and mechanisms. Acta Neuropathol Commun 2: 80. doi:10.1186/s40478014-0080-3

Subramanian A, Tamayo P, Mootha VK, Mukherjee S, Ebert BL, Gillette MA, Paulovich A, Pomeroy SL, Golub TR, Lander ES, et al (2005) Gene set enrichment analysis: A knowledge-based approach for interpreting 
genome-wide expression profiles. Proc Natl Acad Sci U S A 102: 15545-15550. doi:10.1073/pnas.0506580102

Tanaka T, Serneo FF, Higgins C, Gambello MJ, Wynshaw-Boris A, Gleeson JG (2004) Lis1 and doublecortin function with dynein to mediate coupling of the nucleus to the centrosome in neuronal migration. J Cell Biol 165: 709-721. doi:10.1083/jcb.200309025

Tatton-Brown K, Murray A, Hanks S, Douglas J, Armstrong R, Banka S, Bird LM, Clericuzio CL, Cormier-Daire V, Cushing T, et al (2013) Weaver syndrome and EZH2 mutations: Clarifying the clinical phenotype. Am J Med Genet A 161A: 2972-2980. doi:10.1002/ajmg.a.36229

Tenney AP, Livet J, Belton T, Prochazkova M, Pearson EM, Whitman MC, Kulkarni AB, Engle EC, Henderson CE (2019) Etv1 controls the establishment of non-overlapping motor innervation of neighboring facial muscles during development. Cell Rep 29: 437-452. doi:10.1016/ j.celrep.2019.08.078

Thiery JP, Acloque H, Huang RY, Nieto MA (2009) Epithelial-mesenchymal transitions in development and disease. Cell 139: 871-890. doi:10.1016/ j.cell.2009.11.007

Tsai JH, Yang J (2013) Epithelial-mesenchymal plasticity in carcinoma metastasis. Genes Dev 27: 2192-2206. doi:10.1101/gad.225334.113

Tsai JW, Chen Y, Kriegstein AR, Vallee RB (2005) LIS1 RNA interference blocks neural stem cell division, morphogenesis, and motility at multiple stages. J Cell Biol 170: 935-945. doi:10.1083/jcb.200505166

Tsai LH, Gleeson JG (2005) Nucleokinesis in neuronal migration. Neuron 46: 383-388. doi:10.1016/j.neuron.2005.04.013

Tsurusaki Y, Koshimizu E, Ohashi H, Phadke S, Kou I, Shiina M, Suzuki T, Okamoto N, Imamura S, Yamashita M, et al (2014) De novo SOX11 mutations cause Coffin-Siris syndrome. Nat Commun 5: 4011. doi:10.1038/ncomms5011

Umeshima H, Hirano T, Kengaku M (2007) Microtubule-based nuclear movement occurs independently of centrosome positioning in migrating neurons. Proc Natl Acad Sci U S A 104: 16182-16187. doi:10.1073/pnas.0708047104

van Groningen T, Koster J, Valentijn LJ, Zwijnenburg DA, Akogul N, Hasselt NE, Broekmans M, Haneveld F, Nowakowska NE, Bras J, et al (2017) Neuroblastoma is composed of two super-enhancer-associated differentiation states. Nat Genet 49: 1261-1266. doi:10.1038/ng.3899

van Zijl F, Mall S, Machat G, Pirker C, Zeillinger R, Weinhaeusel A, Bilban M, Berger W, Mikulits W (2011) A human model of epithelial to mesenchymal transition to monitor drug efficacy in hepatocellular carcinoma progression. Mol Cancer Ther 10: 850-860. doi:10.1158/ 1535-7163. mct-10-0917

Vasudevan S, Steitz JA (2007) AU-rich-element-mediated upregulation of translation by FXR1 and Argonaute 2. Cell 128: 1105-1118. doi:10.1016/ j.cell.2007.01.038

Verissimo CS, Molenaar JJ, Meerman J, Puigvert JC, Lamers F, Koster J, Danen EHJ, van de Water B, Versteeg R, Fitzsimons CP, et al (2010) Silencing of the microtubule-associated proteins doublecortin-like and doublecortin-like kinase-long induces apoptosis in neuroblastoma cells. Endocr Relat Cancer 17: 399-414. doi:10.1677/erc-09-0301

Viprey VF, Gregory WM, Corrias MV, Tchirkov A, Swerts K, Vicha A, Dallorso S, Brock P, Luksch R, Valteau-Couanet D, et al (2014) Neuroblastoma mRNAs predict outcome in children with stage 4 neuroblastoma: A European HR-NBL1/SIOPEN study. J Clin Oncol 32: 1074-1083. doi:10.1200/jco.2013.53.3604

Walton JD, Kattan DR, Thomas SK, Spengler BA, Guo H-F, Biedler JL, Cheung NKV, Ross RA (2004) Characteristics of stem cells from human neuroblastoma cell lines and in tumors. Neoplasia 6: 838-845. doi:10.1593/neo.04310
Westermann F, Muth D, Benner A, Bauer T, Henrich KO, Oberthuer A, Brors B, Beissbarth T, Vandesompele J, Pattyn F, et al (2008) Distinct transcriptional MYCN/C-MYC activities are associated with spontaneous regression or malignant progression in NBs. Genome Biol 9: R150. doi:10.1186/gb-2008-9-10-r150

White PS, Thompson PM, Seifried BA, Sulman EP, Jensen SJ, Guo C, Maris JM Hogarty MD, Allen C, Biegel JA, et al (2001) Detailed molecular analysis of 1 p36 in neuroblastoma. Med Pediatr Oncol 36: 37-41. doi:10.1002/ 1096-911x(20010101)36:1<37::aid-mpo1010>3.0.co;2-

Wu JH, Fanaroff AC, Sharma KC, Smith LS, Brian L, Eipper BA, Mains RE, Freedman NJ, Zhang L (2013) Kalirin promotes neointimal hyperplasia by activating Rac in smooth muscle cells. Arterioscler Thromb Vasc Biol 33: 702-708. doi:10.1161/ATVBAHA.112.300234

Xie X, Lu J, Kulbokas EJ, Golub TR, Mootha V, Lindblad-Toh K, Lander ES, Kellis M (2005) Systematic discovery of regulatory motifs in human promoters and 3' UTRs by comparison of several mammals. Nature 434: 338-345. doi:10.1038/nature03441

Xie Z, Sanada K, Samuels BA, Shih H, Tsai LH (2003) Serine 732 phosphorylation of FAK by Cdk5 is important for microtubule organization, nuclear movement, and neuronal migration. Cell 114 469-482. doi:10.1016/s0092-8674(03)00605-6

Yan Y, Eipper BA, Mains RE (2015) Kalirin-9 and Kalirin-12 play essential roles in dendritic outgrowth and branching. Cereb Cortex 25: 3487-3501. doi:10.1093/cercor/bhu182

Yang T, Sun Y, Zhang F, Zhu Y, Shi L, Li H, Xu Z (2012) POSH localizes activated Rac1 to control the formation of cytoplasmic dilation of the leading process and neuronal migration. Cell Rep 2: 640-651. doi:10.1016/ j.celrep.2012.08.007

Yingling J, Youn YH, Darling D, Toyo-Oka K, Pramparo T, Hirotsune S, Wynshaw-Boris A (2008) Neuroepithelial stem cell proliferation requires LIS1 for precise spindle orientation and symmetric division. Cell 132: 474-486. doi:10.1016/j.cell.2008.01.026

Yoon S, Nguyen HCT, Jo W, Kim J, Chi S-M, Park J, Kim S-Y, Nam D (2019) Biclustering analysis of transcriptome big data identifies conditionspecific microRNA targets. Nucleic Acids Res 47: e53. doi:10.1093/nar/ gkz139

Youn YH, Pramparo T, Hirotsune S, Wynshaw-Boris A (2009) Distinct dosedependent cortical neuronal migration and neurite extension defects in Lis1 and Ndel1 mutant mice. J Neurosci 29: 15520-15530. doi:10.1523/ jneurosci.4630-09.2009

Zeid R, Lawlor MA, Poon E, Reyes JM, Fulciniti M, Lopez MA, Scott TG, Nabet B Erb MA, Winter GE, et al (2018) Enhancer invasion shapes MYCNdependent transcriptional amplification in neuroblastoma. Nat Genet 50: 515-523. doi:10.1038/s41588-018-0044-9

Zeinieh M, Salehi A, Rajkumar V, Barker PA (2015) p75NTR-dependent Rac1 activation requires receptor cleavage and activation of an NRAGE and NEDD9 signaling cascade. J Cell Sci 128: 447-459. doi:10.1242/jcs.152173

Zeisel A, Hochgerner H, Lönnerberg P, Johnsson A, Memic F, van der Zwan J, Häring M, Braun E, Borm LE, La Manno G, et al (2018) Molecular architecture of the mouse nervous system. Cell 174: 999-1014. doi:10.1016/j.cell.2018.06.021

Zhu Y, Guthrie S (2002) Expression of the ETS transcription factor ER81 in the developing chick and mouse hindbrain. Dev Dyn 225: 365-368. doi:10.1002/dvdy.10166

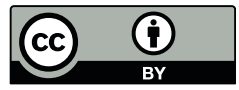

License: This article is available under a Creative Commons License (Attribution 4.0 International, as described at https://creativecommons.org/ licenses/by/4.0/) 